\title{
Heat transfer and pressure drop in the transitional flow regime for a smooth circular tube with twisted tape inserts and a square-edged inlet
}

\author{
J.P. Meyer* and S.M. Abolarin \\ *Author for correspondence
}

Department of Mechanical and Aeronautical Engineering, University of Pretoria, Pretoria, 0002, South Africa, Email: josua.meyer@up.ac.za

\section{HighLights}

- Experimental investigation of transitional flow regime in tubes with twisted tapes.

- Results based on heat transfer coefficients and pressure drops.

- Transitional flow regime was influenced by variation in twist ratios.

- Variation in heat fluxes influenced the transitional flow regime.

- Transition is earlier as the twist ratios and heat fluxes reduced.

\begin{abstract}
The purpose of this study was to experimentally investigate the heat transfer and pressure drop characteristics in the transitional flow regime of twisted tape inserts in a circular tube. Experiments were conducted in a circular tube with an internal diameter of $19.0 \mathrm{~mm}$ and a length of $5.27 \mathrm{~m}$, and twisted tape inserts with twist ratios of 3, 4 and 5. A square-edged geometry was used at the tube inlet and it was experimentally operated with water flowing through it while the tube was heated with a constant heat flux. The experiments were conducted at three different heat fluxes of 2,3 and $4 \mathrm{~kW} / \mathrm{m}^{2}$. The experimental set-up was operated between Reynolds numbers of 400 and 11 400, and the Prandtl numbers varied between 2.9 and 6.7. Two methods were used to identify the transition points of the different heat fluxes and twist ratios. The first method used the standard deviation of the temperature measurements, and the second method used three linear curve fits on a log-log scale. The curve fits made it possible for correlations to
\end{abstract}


be developed for the non-dimensionalised heat transfer coefficients and friction factors, which took twist ratio, heat flux and Reynolds number into consideration. For the same heat flux, it was found that the Colburn $j$-factors increased as the twist ratios decreased, and transition started earlier. When the twist ratio was kept constant and the heat flux was varied, higher heat fluxes delayed the transition from laminar to transitional flow. The friction factors were found to increase as the twist ratio decreased. When both the twist ratio and the Reynolds number were kept constant, an increase in heat flux was found to decrease the friction factor.

Keywords: Heat transfer enhancement, transitional flow regime, Nusselt number, Colburn $j$ factor, twisted tape insert, square-edged inlet, swirl flow, pressure drop, friction factor

\author{
Nomenclature \\ $a$ \\ axis intercept of the linear equations for the twisted tape insert \\ $A_{c} \quad$ cross-sectional area \\ constant \\ c slope of the linear equations \\ Cp $\quad$ specific heat capacity at constant pressure \\ $d \quad \mathrm{y}$-axis intercept of the linear equations in the smooth tube \\ D diameter of the test section \\ $e b \quad$ energy balance error \\ f friction factor \\ $f_{r} \quad$ frequency \\ $h \quad$ heat transfer coefficient
}




\begin{tabular}{ll}
$H$ & pitch; axial distance for a $180^{\circ}$ rotation in twist \\
$I$ & current \\
$j$ & Colburn $j$-factor \\
$k$ & thermal conductivity of the fluid \\
$L$ & length \\
$\dot{m}$ & mass flow rate \\
$N u$ & Nusselt number \\
$P$ & pressure \\
$P r$ & Prandtl number \\
$\dot{q}$ & heat flux \\
$\dot{Q}$ & heat transfer rate \\
$R e$ & Reynolds number \\
$t$ & time \\
$T$ & temperature \\
$T F R$ & transitional flow regime \\
$V$ & voltage \\
$W$ & tape width \\
$x$ & axial position measured from tube inlet \\
$y$ & twist ratio $(H / W)$ \\
\hline &
\end{tabular}

\section{Greek symbol}

$\delta$

thickness of the twisted tape insert

$\mu$

dynamic viscosity 
standard deviation

\section{Subscripts}

$\begin{array}{ll}1,2,3, \ldots, n & \text { station number from station } n=1 \text { to station } n=21 \\ b r & \text { bulk, beginning of transition } \\ c r & \text { critical } \\ e & \text { exit, electrical, end of transition, outer } \\ h & \text { heated length, hydrodynamic entrance length } \\ i & \text { inlet, inner } \\ L & \text { laminar } \\ m & \text { mean } \\ P & \text { pressure } \\ R & \text { transition } \\ s & \text { surface } \\ T & \text { turbulent } \\ T & \text { water }\end{array}$




\section{Introduction}

Heat exchangers are found in domestic applications [1], industrial processes such as manufacturing, food processing and chemical plants $[2,3]$, power stations that use fossil, nuclear or renewable energy sources [4], etc. In most of these cases, heat exchangers were designed to operate either in the laminar or the turbulent flow regime. Usually the transitional flow regime is avoided [5], as this flow regime is not yet well understood [6]. Predictions are unreliable [7], uncertain and unstable [8], the behaviour is complex [9] and the mechanism of transition is unclear [10]. Furthermore, it can be regarded as a metastable and complicated region because the transitional flow regime is characterised by different transport phenomenon [11].

There are specifically two groups that have dedicated attention to experimental investigations in the transitional flow regime. The first groundbreaking work was performed by Ghajar and his co-workers from Oklahoma State University [12-16], and the second by Meyer and his coworkers at the University of Pretoria [1, 5, 17-20]. Ghajar and his co-workers investigated three different types of inlets at constant heat flux conditions in smooth tubes (macro and micro). Their most important finding was that the inlet geometry influenced the transition characteristics inside tubes.

Meyer and co-workers found in general the same dependency of inlet geometry on transitional characteristics. However, they generated results for cooling experiments with wall temperatures that remained almost constant. Their tubes also had internally spiralled fins. They also conducted experimental investigations in the transitional flow regime using nanofluids [19] and micro channels [17] at different heat fluxes.

Both Ghajar and Meyer not only conducted their experiments with different types of inlets, but also with calming sections upstream of the different types of inlets, to dampen out upstream 
flow disturbances. The geometries of the calming sections used by Meyer were based on the design of Ghajar's calming section.

Furthermore, Meyer used an accumulator between the pump and the calming section to dampen out the pressure pulsations caused by the pump. Meyer and his co-workers also operated the pump with high back pressure, using a bypass valve to further decrease the flow pulsations. Ghajar and his co-workers conducted limited experiments with different screens at the end of the calming section and found that the different types of screens influenced the commencement of the transitional flow regime. It therefore seems that the effect of accumulators and/or the geometry of calming sections (i.e. contraction ratio and length, as well as the content such as meshes, screens and straws), on the disturbances at the inlet, have not yet been investigated in detail.

It is therefore possible that the use of an accumulator might also influence the transition characteristics in tubes. This was confirmed by Everts and Meyer [21]. The influence was such that the fluctuation in the mass flow rate was reduced by $85 \%$ [22]. Therefore, it is important for transitional flow experiments that not only the details of the inlet geometry are specified, but until more information is available - also the detailed geometry and content of both the calming section and the accumulator.

Although the majority of the work of Ghajar and Meyer was on smooth macro tubes varying in diameter from 4 - $19 \mathrm{~mm}$, sufficient other experiments were conducted with micro channels, enhanced tubes and different types of fluids varying in Prandtl numbers from 4 - 158, that show the same dependency on the inlet geometry. It can therefore the concluded that the transitional behaviour of tubes with twisted tape inserts should be influenced not only by the 
type of inlet, but also by the calming section and possibly the accumulator. This has not been reported previously in the literature, specifically not for twisted tapes.

In the following review on previous work done using twisted tape inserts, cases occurred where experiments were most probably in the transitional flow regime. However, no specific attention was given to this regime, and it was either reported as part of the laminar or turbulent flow regimes, or as part of both regimes. The geometry effects of the inlets were not considered and, in some cases, a tube length with the same diameter as the test section, was considered as a calming section. This ensured hydrodynamic fully developed flow since there was no contraction ratio. No work had been done for other inlet configurations that will cause a contraction as the fluid flows into the test section.

The use of twisted tape inserts as a passive enhancement technique under uniform heat flux boundary conditions was first investigated by Hong and Bergles [23], who carried out an experimental investigation in the laminar regime over a range of Reynolds numbers from 13 2260 with water and ethylene glycol as the working fluids. This range of Reynolds numbers was reported as being laminar without any references to a transitional flow regime. In the concluding remarks, the study recommended experimental investigation in the transitional flow regime, as this would serve as a basis of providing an all-encompassing correlation for the laminar and turbulent flow regimes.

Wongcharee and Eiamsa-ard [24] reported characteristics of heat transfer in laminar swirl flow conditions with twisted tape inserts that alternated between clockwise and counterclockwise for Reynolds numbers from 830 - 1 990. The study obtained a maximum heat transfer improvement of $5.25 \%$ at a Reynolds number of 830 . 
Experiments performed with regularly spaced twisted-tape inserts, with a single twist in the tape module and connected by thin circular rods, were conducted by Saha, et al. [25] over a laminar range of Reynolds numbers from 45 - 1150 with servotherm oil as the working fluid. It was found that phase angles higher than zero, were of no use. However, the differences between the heated and isothermal friction factors for the periodic swirl flow, were substantially less than for the flow through plain tubes.

Other experimental studies on twisted tape inserts are the work of Watanabe, et al. [26], which used air as the working fluid, and Bandyopadhyay, et al. [27], which used oil as the working fluid. Computational investigations in the laminar flow regime include the work of Date [28] and Date and Gaitonde [29]. However, in general in all these studies, the transitional flow regime was not identified and/or discussed, or very little attention was given to it, as it was not the primary focus or purpose of their studies.

In the turbulent flow regime, several studies investigated the use of twisted tape inserts using a constant heat flux boundary condition and a Reynolds number range of $4000-25000$. Both Eiamsa-ard, et al. [30] and Bas and Ozceyhan [31] used air as the working fluid, while Seemawute and Eiamsa-ard [32] used water as the working fluid. These studies were only carried out for the purpose of characterising the heat transfer enhancement of twisted tapes over smooth tubes, and not for the establishment of the boundaries of the three (laminar, transitional and turbulent) flow regimes.

Other passive enhancement techniques that have been investigated include delta-winglet twisted tape insert by Eiamsa-ard, et al. [33] using water as the working fluid. This produced heat transfer enhancements of 1.02 - 1.64 times that of a smooth tube in the turbulent Reynolds number range of 3000 - 27000 . A combination of wire coil and twisted tape inserts was 
investigated by Promvonge [34] using air, for Reynolds numbers between $3000-18000$ and a doubling of the heat transfer rate was found. Increased Nusselt numbers with the use of serrated, broken, ribbed, spiky and multiple twisted tape inserts have also been reported [35-39]. All these studies have demonstrated various passive techniques using twisted tape inserts to achieve heat transfer enhancement in tubes. However, they were all limited to the laminar and turbulent flow regimes.

Manglik and Bergles [40] experimentally investigated over a Reynolds number range of 300 30000 , twisted tape inserts using a uniform wall temperature boundary condition. They concluded that the progression from transition to turbulent is usually characterised with instabilities in flow and fluctuations in velocity, that centrifugal forces suppress these instabilities and fluctuations, and that secondary flows dampen the turbulent pulsations and thus delay transition [41]. A delayed transition to turbulent flow with the use of twisted tape inserts has also been reported in Watanabe, et al. [26], Donevski and Kulesza [42] and Nair [43]. The critical Reynolds number, that indicates the commencement of a transitional flow regime, of 6360 reported by Watanabe, et al. [26], was in total disagreement with the critical Reynolds number of 30430 which was provided by Donevski and Kulesza [42]. In these two papers, these critical Reynolds numbers were chosen as the point of intersection between the laminar and the turbulent flow regimes. There was no range of Reynolds numbers clearly defining and differentiating the transition region from laminar to turbulent flow.

Based on flow regime maps, Manglik and Bergles [41] stated that flow rates with Reynolds numbers less than 10000 fall within the transitional flow regime and higher flow rates could be regarded as fully developed turbulent flow. In some cases, turbulent flow may be achieved at lower Reynolds numbers, depending on the twist ratios of the twisted tape inserts used. 
Furthermore, for the purpose of designing heat exchangers, the study recommended curve fittings of experimental data from the laminar to the turbulent flow regimes, in order to quantify heat transfer coefficients and friction factors in the transitional flow regime.

Bharadwaj, et al. [44], experimentally investigated the heat transfer and pressure drop in a spirally grooved tube with twisted tape inserts. Laminar to fully turbulent Reynolds numbers from approximately 300 to 25000 were considered. The three most important observations made were: (1) it appeared that transition-like characteristics for a grooved tube without a twisted tape insert started at approximately a Reynolds number of 3000 and continued up to a Reynolds number of 7 000. (2) there was no abrupt change in the friction factor in the transitional flow regime with twisted tape insert. (3) a transition-like abrupt change in the Nusselt number with the twisted tape insert was observed at a Reynolds number of 7000 . They have also produced equations for friction factors and Nusselt numbers in the three flow regimes of laminar, transitional and turbulent. However, this was for a grooved tube with a twisted tape insert, not for a smooth tube with a twisted tape (as in this study). Limited considerations/details were also given to the possible effects of the connection of the test section to the calming section to ensure limited boundary layer disturbances effects. Also, it appears as if the calming section length will not ensure a fully hydrodynamically developed velocity distribution at the test section inlet (based on $L_{h}=0.05 R e D$, at a transition Reynolds number of 3000 and a diameter of $12.5 \mathrm{~mm}$, it will take approximately $1.9 \mathrm{~m}$ for the flow to get fully developed, while the calming section length was $1.2 \mathrm{~m}$ ). The inlet velocity distribution is an important factor to take into consideration as was shown by Ghajar and co-workers $[12,13,45,46]$ as well as Meyer and co-workers [1, 20, $22,47]$. They showed that another calming section length and/or geometry will influence the critical Reynolds number as well as the characteristics of the friction factors and heat transfer 
coefficients in the transitional flow regime. It is conceded, that as enhancement techniques such as both grooved tubes and twisted tapes were used in the study of Bharadwaj, et al. [44], that the effects might be less significant than for smooth tubes.

That the inlet geometry will influence the critical Reynolds number as well as the transitional results for not only smooth tubes but also for enhanced tubes, has been illustrated for not only the friction factors by Tam, et al. [48], but also the heat transfer by Tam, et al. [49]. This has been independently verified by Meyer and Olivier [22] and Meyer and Olivier [50]. In Tam, et al. [48] for example, the effect on heat transfer in the transitional flow regime of three different types of inlet geometries on microfin tubes were experimentally studied. The different types of inlets were a square-edged, re-entrant, and bellmouth inlet. Meyer and Olivier [22, 50] also included in their studies a long enough tube length (calming section) to ensure hydrodynamically fully developed flow. This type of inlet corresponds to the type of inlet used by Bharadwaj, et al. [44], however, it was longer (160D as recommended by Durst, et al. [51]) to ensure hydrodynamically fully developed flow at the test section inlet. Tam, et al. [49] showed that the transitional flow regime starts and ends at Reynolds numbers of 1946 - 8105, 2144 - 8254 and 3015 - 8092, respectively for a re-entrant, square-edged and bellmouth type of inlet geometries. It was therefore concluded by them that the geometry of the inlet influenced the start and end of transition.

In general, a lot of work has been done on twisted tapes. According to Scopus over the threeyear period 2014-2016, more than 240 publications were produced using the two keywords "twisted" and "tapes' in the title, abstract or keywords. The most recent and relevant, 30 are references [52-81]. Of these only two [61,73] mentioned transition. 
$\mathrm{Ji}$, et al. [61] presented a review article of experimental studies on heat transfer and performance enhancements conducted in the laminar, transitional and turbulent flow regimes for four passive enhancement techniques. The enhancement techniques considered were integralfins, twisted tape inserts, corrugated tubes and dimple tubes. It was found that specifically twisted tapes were very effective in the laminar and transitional flow regimes and that they may be more suitable for fluids with high viscosities.

Bhadouriya, et al. [73], conducted an experimental and numerical investigation of friction factors and heat transfer characteristics of air flowing through a twisted square duct. The twist ratios of the ducts were 11.5 and 16.5 and experiments were conducted for Reynolds numbers of 600 to 70000 . The Reynolds number range for the numerical study varied between 100 to 100000 and the twist ratios were $2.5,5,10$, and 20. The start of transition was observed during the experimental study at a Reynolds number of 2900 for the duct with a twist ratio of 11.5, and at a Reynold number of 3000 for the duct with a twist ratio of 16.5 . The transition to turbulent was assumed to have commenced when there was a sudden change in the slope of both the friction factor and heat transfer data in the laminar flow regime.

A review of the literature on the transitional flow regime, specifically of twisted tape inserts, identified two gaps in the literature. Firstly, that little work has been conducted on heat transfer in the transitional flow regime. Some studies [40, 41, 82, 83] included some experimental work in the transitional flow regime, but did not concentrate specifically on the transitional flow regime. Secondly, when transitional flow experiments are conducted, it is essential that the inlet geometry, calming section and accumulator are taken into consideration and documented as part of the study. This was not done in previous work on twisted tape inserts in tubes in the transitional flow regime. Therefore, the purpose of this study was to experimentally determine 
the heat transfer and pressure drop characteristics in the transitional flow regime with twisted tape inserts inside smooth tubes using a square-edged inlet. Water was used as the working fluid and a squared-edged inlet geometry was used as an inlet. More details than usual were also given on the inlet geometry, calming section and specifically the accumulator that were used in this study. The inlet geometry of a square edged was used, as it is the type of geometry that is simple to be replicated and manufactured by other laboratories, and to be used as an inlet boundary condition for numerical simulations. It is also the type of geometry found in many heat exchangers such as shell-and-tube heat exchangers, where the flow inlet through each tube is from a common header.

\section{Experimental set-up}

The experimental set-up in which heating was conducted on the test section is shown schematically in Fig. 1. The most important components in the set-up were labelled from 1 to 16 , which were part of a water circulation loop.

\subsection{Components of circulation loop}

The water that was heated in the test section was cooled and maintained at a constant temperature in a cold water reservoir (1) that was connected to a chiller unit (2). The water was pumped (3) through a water loop in which there was an accumulator (4), valves (5) used to operate the bypass line and/or bank of flow meters (6), an inlet mixer (7), calming section (8), square-edged inlet (9), test section (10), pressure transducer (11), power supply(12), data acquisition system (13), exit mixer (14), hot water reservoir (15) and hot water pump (16). Where relevant, more details are given below for each of the 16 components of the experimental set-up. 


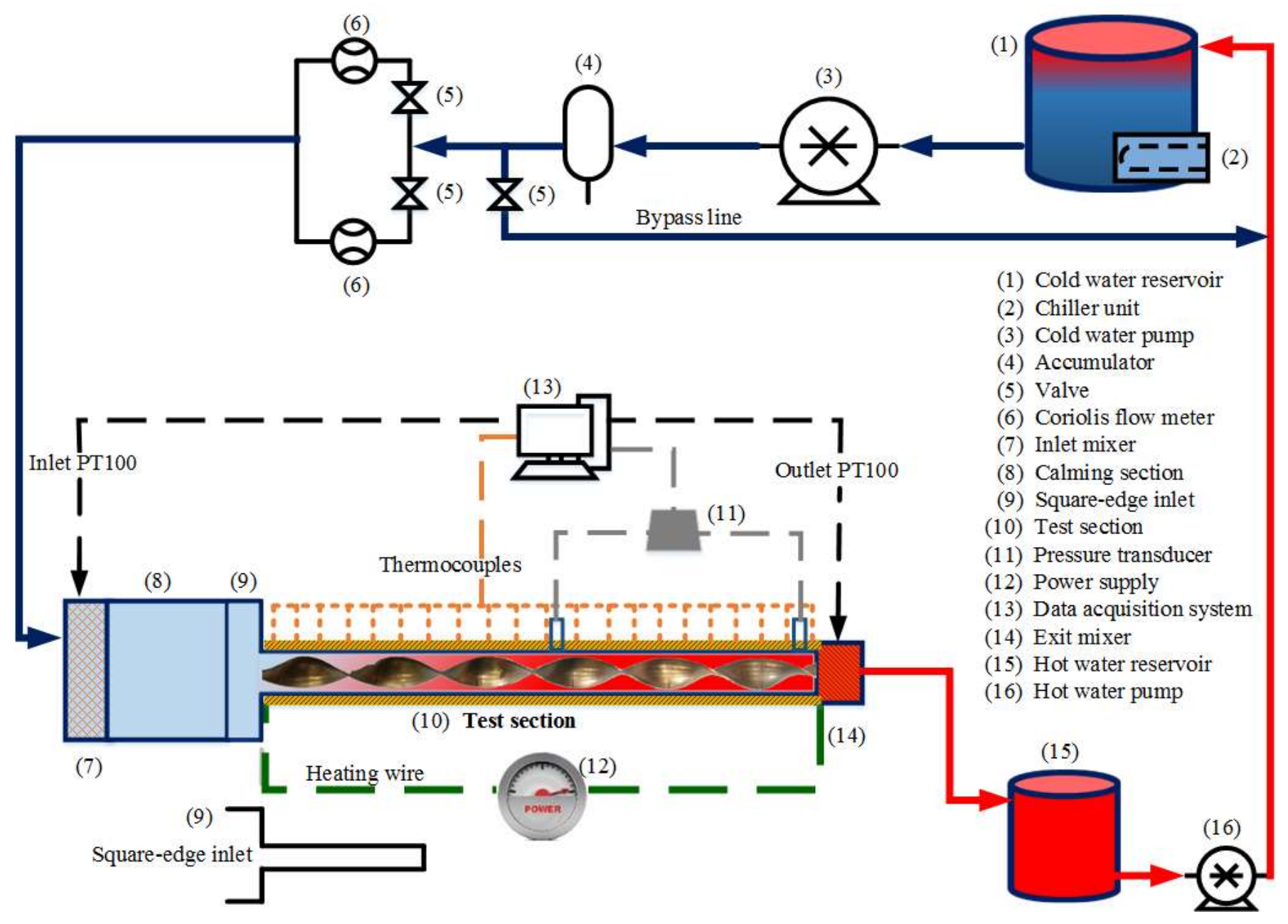

Fig. 1. Schematic diagram of the experimental set-up. The numbers (1) to (16) are described in Section 2.

The capacity of the cold water reservoir (1) was $5000 \ell$ and the tank was well insulated to prevent heat transfer to and from the environment. The tank and the experimental set-up were in a non-air-conditioned laboratory in which the ambient air temperatures varied from approximately $15-25^{\circ} \mathrm{C}$. The water in the tank was continuously circulated through an aircooled chiller unit (2) with a capacity of $15 \mathrm{~kW}$, and the temperature in the water reservoir was thermostatically controlled to approximately $20^{\circ} \mathrm{C}$. The cold water pump (3) was a positive displacement type of pump that could be controlled electronically with variable speed drives and 
could pump the water through the circulation loop at volume flow rates varying from 6 -

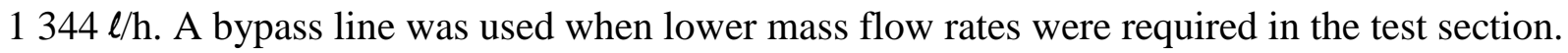

The function of the accumulator (4) was to dampen possible flow pulsations caused by the positive displacement pump [21, 22]. The accumulator was of the Hydac bladder type with a diameter, height and volume of $173 \mathrm{~mm}, 419 \mathrm{~mm}$, and $4 \ell$, respectively. It was charged with nitrogen to an operating pressure of $3.3 \mathrm{MPa}$ and the maximum operating mass flow rate was $10 \mathrm{~kg} / \mathrm{s}$.

A bypass valve (5) was installed between the accumulator (4) and the bank of two different sized Coriolis mass flow meters (6), each with its own range of accuracies. The valves were installed to make it possible to switch between the Coriolis mass flow meters, as well as to allow water to flow back into the cold water reservoir. In general, it was found that the mass flow fluctuations increased as the pump speed decreased, and the flow fluctuations were the smallest at the highest pump speed [18]. Therefore, the pump was always operated at the highest possible pump speed, and lower mass flow rates (with low mass flow fluctuations) were achieved by controlling the flow opening of the valve in the bypass line.

The mass flow rates of the water through the test section were measured by selecting one of the two Coriolis flow meters (6) with the appropriate flow range. The flow ranges were 4 $108 \mathrm{l} / \mathrm{h}$ (usually in the laminar and transitional flow regimes) for low mass flow rate measurements, and $54-2180 \mathrm{l} / \mathrm{h}$ for high mass flow rate measurements (usually in the turbulent flow regime). The measurement errors of both mass flow meters, when operated in their prescribed ranges, were $0.05 \%$.

The calming and inlet section consisted of three parts (Fig. 3): an inlet mixer (7), the calming section (8), and the square-edged inlet (9). The functions of the inlet mixer were to mix the water 
to ensure that no temperature gradient was present at the inlet of the tube, and to accurately measure the water inlet temperature. The inlet mixer (7) consisted of stainless steel shavings, as shown schematically in Fig. 2, with a Pt100 probe in the centre, to measure the water inlet temperature.

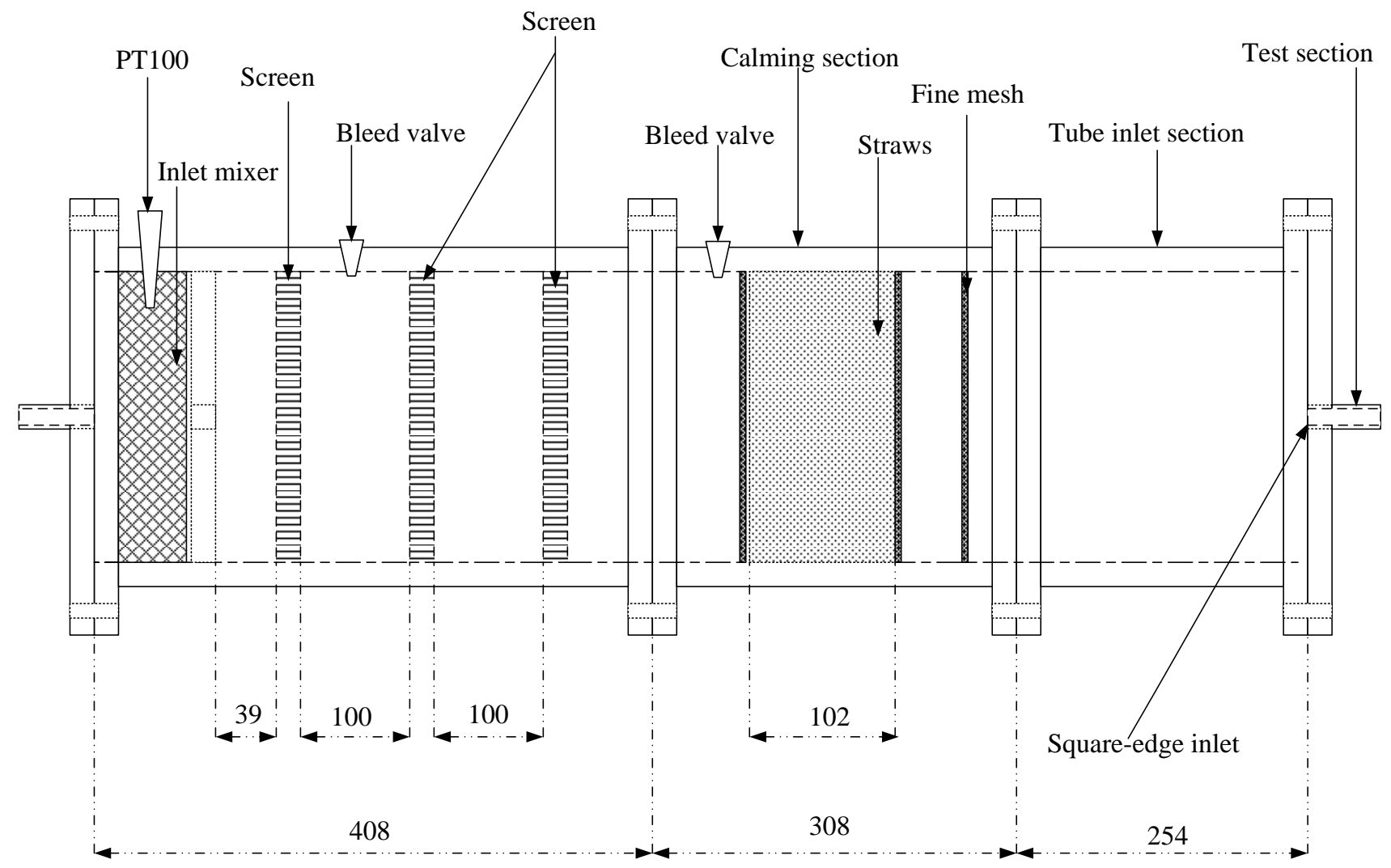

Fig. 2. A schematic diagram of the calming section with square-edged inlet configuration based on the calming section used by Tam, et al. [45]. 


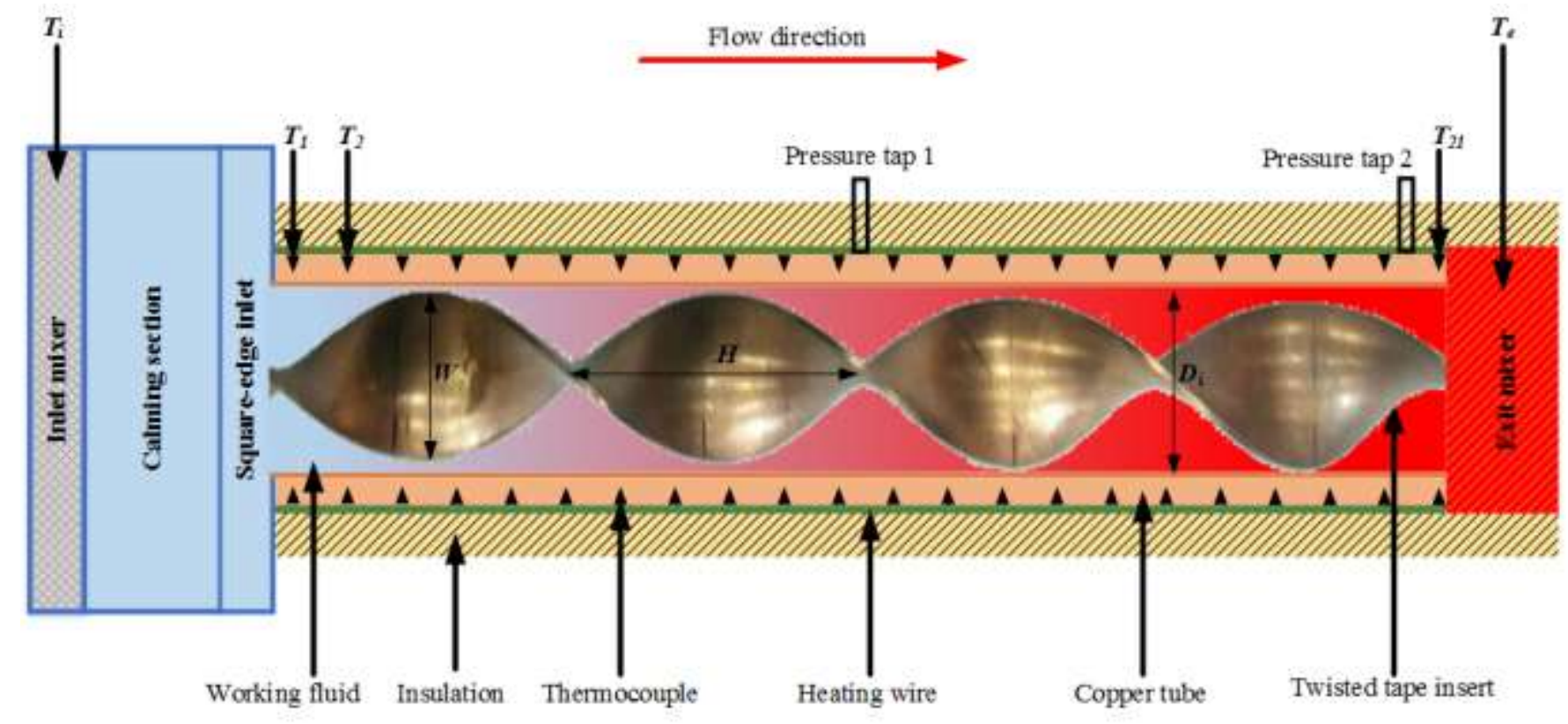

Heated length

Fig. 3. Schematic diagram (not to scale) of the test section showing the positioning of the inlet mixer, calming section, square-edged inlet, test section, twisted tape, heating wire, insulation, exit mixer, thermocouples and pressure taps.

The calming section(8) placed before the test section played two major roles in the experimental set-up and data measurement. First to ensure a uniform fluid velocity distribution entering the test section and second to accommodate the square-edged inlet (9), considered in this study.

This calming and inlet section shown in Fig. 2 was based on the design of Ghajar and coworkers $[12,13,45,46,84]$ and, in general, was similar except for four notable differences:

- The inlet mixer was integrated to be part of the inlet of the calming section by increasing the length of the cylindrical geometry of the calming section.

- The material used was not acrylic plastic, but stainless steel (the "straws", screens and meshes were also manufactured from stainless steel), to ensure that the calming section 
could withstand higher pressures than acrylic plastic for other experiments that were planned with propylene glycol as the working fluid.

- The calming section's inner diameter was $200 \mathrm{~mm}$, which gave a larger contraction ratio of about 10.5, compared to Ghajar and Tam [12] and Tam, et al. [45], who used a $146 \mathrm{~mm}$ inner diameter acrylic tube and a contraction ratio of 9.24 .

- The connection of the square-edged to the test section was simpler and different as it was not planned to accommodate a bellmouth inlet as was done by Tam, et al. [45].

The last part of the calming section was the inlet section, which accommodated the squareedged inlet (9). This inlet was achieved by ensuring that the test section (10) was assembled to be flush with the last flange of the inlet section. Both the inlet section and the test section were concentric. Two bleed valves were installed onto the calming section that were used to bleed out air before and during experimentation. Components 11 to 14 were part of the test section and are discussed in Section 2.2.

The exit mixer (14) connected to the outlet of the test section was made from a nylon rod with a $50 \mathrm{~mm}$ outer diameter and length of $200 \mathrm{~mm}$. A hole of $19 \mathrm{~mm}$ was drilled through this rod to accommodate a copper plate mixer tightly inserted into the hole. The mixer consisted of four copper helically twisted splitter plates. The sensor of the Pt100 probe was installed downstream of the mixer with all the fluid flowing in an axial direction over the total length of the sensor to ensure that the average exit temperature was measured accurately. Both the inlet and outlet Pt100 probes were calibrated to within $0.06^{\circ} \mathrm{C}$, in a thermal bath over a temperature range of 15 to $60^{\circ} \mathrm{C}$ against a calibrated Pt100 within an error of less than $0.01^{\circ} \mathrm{C}$. 
The hot working fluid leaving the exit mixer flowed into a hot water reservoir (15) from which the water was continuously pumped with a positive displacement pump (16) back to the cold water reservoir (1) of the experimental set-up.

\subsection{Test section}

The test section (10), as shown in Fig. 1 and enlarged in Fig. 3, was used for two different experiments. The first was for smooth tube experiments conducted for validation purposes, while the second was for experiments that accommodated twisted tape inserts, used as a passive heat transfer enhancement technique. The test section consisted of a single $5.27 \mathrm{~m}$ smooth copper tube with an inner diameter of $19 \mathrm{~mm}$ and an outer diameter of $22 \mathrm{~mm}$.

Two pressure taps were fixed onto the test section for pressure drop measurements. They were placed on the last part of the test section, so that only fully developed pressure drops were measured. The first pressure tap was placed $2.52 \mathrm{~m}$ from the tube inlet, and the second pressure tap was placed $4.97 \mathrm{~m}$ from the inlet. The distance between the pressure taps was thus $2.45 \mathrm{~m}$. The first pressure tap distance was conservatively estimated using the formula for the laminar forced convection thermal entrance length, of $L_{t h}=0.05 \operatorname{RePrD}$. This is a conservative distance as mixed convection will ensure that the flow will be fully developed at a shorter distance from the inlet. (It will be shown later in the results that the flow was thermally fully developed long before the first pressure tap.)

The pressure tap holes were drilled with a high-speed drill bit to prevent burrs from forming on the inner tube surface. Care was taken to ensure that any small burrs that may have formed were removed. The diameter of the holes was $1.6 \mathrm{~mm}$, and they were less than $10 \%$ of the inner tube diameter, as prescribed by Rayle [85], to prevent localised eddies from affecting the 
pressure drop measurements. The pressure drops were measured with a differential pressure transducer (11) containing a $1.4 \mathrm{kPa}$ diaphragm for the smooth tube and a $3.5 \mathrm{kPa}$ diaphragm for the tube with twisted tape inserts. The diaphragms were calibrated with an accuracy of 3.5 $\mathrm{Pa}$ and $8.75 \mathrm{~Pa}$ respectively over a pressure range of $0 \mathrm{~Pa}$ to their respective maximum pressures.

A total of 84 thermocouples were also soldered onto the test section, and used to measure the surface temperature of the test section at different axial positions. The thermocouples were of the T-type, and $0.25 \mathrm{~mm}$ in diameter. The thermocouples were installed at 21 locations along the test length. Each station contained four thermocouples at angles of $0^{\circ}$ (top), $90^{\circ}$ (left), $180^{\circ}$ (bottom) and $270^{\circ}$ (right) on the outer wall of the tube. The first station was positioned $170 \mathrm{~mm}$ from the tube inlet $\left(x / D_{i}=8.9\right)$, and all the other stations were equally spaced $250 \mathrm{~mm}$ from each other. Station 21 was $5.17 \mathrm{~m}$ from the tube inlet $\left(x / D_{i}=272\right)$. All thermocouples were calibrated to within $0.1{ }^{\circ} \mathrm{C}$ (after they were soldered onto the test section), with water circulated from a thermal bath through the test section over a temperature range from $15-60{ }^{\circ} \mathrm{C}$ against a calibrated Pt100 probe.

A constant heat flux boundary condition on the inside tube wall was obtained with electrical heating. Two insulated constantan wires, connected in parallel, were closely coiled around the outer surface of the smooth copper tube and were connected to a direct current power source. Care was taken that the gaps between the heating wires and the thermocouple stations were very small (approximately $1 \mathrm{~mm}$ ) to ensure that the applied heat flux on the outer tube remained constant in an axial length, but that the wires did not touch the thermocouples. The heating wires had a diameter of $0.81 \mathrm{~mm}$ and were connected in parallel to reduce the total electrical resistance, and prevent the heating wires from melting, as the required current for the heat fluxes 
would have been too high for one wire. The power supply (12), as identified in Fig. 1, was rated as $1.5 \mathrm{~kW}$, with a current and voltage range of $0-15 \mathrm{~A}$ and $0-360 \mathrm{~V}$ respectively. The error of the current and the voltage from this power supply was $0.02 \%$ of the nominal value.

To reduce heat loss to the environment, the calming section and test section were insulated with a flexible, closed-cell, elastomeric nitrile rubber material with a low thermal conductivity of $0.037 \mathrm{~W} / \mathrm{mK}$. The overall thickness of the insulation used was $144 \mathrm{~mm}$. With this insulation thickness, the heat losses were estimated with one-dimensional conduction resistance calculations to be less than $1 \%$ of the power input.

The first set of experiments conducted for this study was with a smooth tube, of which the results were compared to literature. The second set of experiments, which was the focus of this study, was achieved by inserting twisted tapes into the smooth tube. The twisted tapes were fabricated from a plain copper sheet with a thickness, $\delta$, of $1 \mathrm{~mm}$, which were cut with a guillotine into strips with a tape width, $W$, of $18 \mathrm{~mm}$, and a length of $1 \mathrm{~m}$. These strips were clamped into the two ends of the jaw chuck and tool post of a lathe. The tool post was held stationary, while the jaw chuck was rotated manually to achieve the desired pitch, $H$, and twist ratio, $y=H / W$. The pitch, $H$, was defined as the axial distance required to complete a $180^{\circ}$ rotation in a twisted tape insert. Several tapes were carefully soldered to form smooth joints to make up a total length of $5.27 \mathrm{~m}$ before they were inserted into the smooth tube test section.

The test section was connected in a longitudinal direction to the stainless steel calming section and the outlet mixer made from nylon. The thermal conductivity values of the stainless steel, copper tube and nylon were 17, 401 and $0.25 \mathrm{~W} / \mathrm{mK}$ respectively. Since the thermal conductivity of the stainless steel and nylon were both at least one order of magnitude lower than that of the copper tube, axial heat conduction to the calming section and mixer were limited. 
All the measurements were recorded with a data acquisition system (13). The instrumentation included flow meters that measured the mass flow rates, T-type thermocouples that measured the surface temperatures, Pt100 probes that measured the fluid bulk inlet and outlet temperatures, and the differential pressure transducer that measured the pressure drops. The outputs of the data streamed through the data acquisition system were logged to a personal computer, which were also used for data reduction.

The geometrical details of three twisted tape inserts with twist ratios of 3,4 and 5, and the experimental operating conditions are given in Table 1. Experiments were conducted at three constant heat fluxes of 2,3 and $4 \mathrm{~kW} / \mathrm{m}^{2}$.

Table 1. Parametric values of the experimental set-up

\begin{tabular}{lcl}
\hline Parameters & Symbols & Values \\
\hline Thickness of twisted tape inserts & $\delta$ & $1 \mathrm{~mm}$ \\
Outer diameter of test section & $D_{e}$ & $22.0 \mathrm{~mm}$ \\
Inner diameter of test section & $D_{i}$ & $19.0 \mathrm{~mm}$ \\
Pitches of the twisted tape inserts & $H$ & $54,72,90 \mathrm{~mm}$ \\
Length of twisted tape/test section & $L$ & $5.27 \mathrm{~m}$ \\
Heat transfer length & $L_{h}$ & $4.8 \mathrm{~m}$ \\
Pressure drop length & $L_{\Delta p}$ & $2.45 \mathrm{~m}$ \\
Prandtl numbers & $P r$ & $2.9-6.7$ \\
Heat fluxes & $\dot{q}$ & $2,3,4 \mathrm{~kW} / \mathrm{m}^{2}$ \\
Reynolds numbers & $R e$ & $400-11400$ \\
Inlet temperature of the working fluid & $T_{i}$ & $20^{\circ} \mathrm{C}$ \\
Width of twisted tape insert & $W$ & $18 \mathrm{~mm}$ \\
Twist ratios & $y$ & $3,4,5$
\end{tabular}




\section{Data reduction}

The mean fluid temperatures at the inlet and outlet of the test section were measured using the Pt100 probes that were installed inside the inlet and exit mixers. The mean water temperature inside the test section increased linearly as it was heated with a constant heat flux. The mean water temperatures, $T_{w}(x)$, at a specific axial location, $x$, through the test section were therefore determined by:

$$
T_{w}(x)=T_{i}+\left[\frac{T_{e}-T_{i}}{L_{h}}\right] * x
$$

where $T_{i}$ and $T_{e}$ were the inlet and outlet temperature measurements, and $L_{h}$ (Fig. 3) was the heated length of the test section. The mean inlet temperatures were taken where $x=0$, and the mean outlet temperatures were taken where $x=L_{e}$.

At all measuring stations, the local temperatures, dynamic viscosities, $\mu_{w}(x)$, densities, $\rho_{w}(x)$, thermal conductivities, $k_{w}(x)$, specific heat capacities, $C p_{w}(x)$, and Prandtl numbers, $P r_{w}(x)$, were determined at each surface measuring station as prescribed by Popiel and Wojtkowiak [86]. These values, were subsequently substituted where needed to obtain the other variables used in the data reduction.

The bulk temperatures, $T_{b}$, of the water of each experiment were determined as the average between the measured inlet and outlet temperatures as:

$$
T_{b}=\frac{T_{i}+T_{e}}{2}
$$

The local Reynolds number, $\operatorname{Re}(x)$, at each surface station was determined from the measured mass flow rate, $\dot{m}_{w}$, of the water flowing through the test section, the measured inner tube diameter, $D_{i}$, the local dynamic viscosity, $\mu_{w}(x)$, at the station and the cross-sectional area, $A_{c}$.

$$
R e(x)=\frac{\dot{m}_{w} D_{i}}{\mu_{w}(x) A_{c}}
$$


The cross-sectional area was determined as $A_{c}=\pi D_{i}^{2} / 4$. The bulk Reynolds number, $R e_{b}$, was determined using the bulk dynamic viscosity, $\mu_{b}$, at the bulk temperature, $T_{b}$, in Eq. (2) as:

$$
R e_{b}=\frac{\dot{m}_{w} D_{i}}{\mu_{b} A_{c}}
$$

For each experiment conducted at a certain bulk Reynolds number, the heat transfer rate, $\dot{Q}_{w}$, to the water:

$$
\dot{Q}_{w}=\dot{m}_{w} C p_{b}\left(T_{e}-T_{i}\right)
$$

was determined from the measured water mass flow rate, the increase in water temperature measurements from inlet $T_{i}$ to outlet $T_{e}$ and the specific heat capacity, $C p_{b}$, which was determined at the bulk temperature as determined from Eq. (2).

The heat transfer rates to the water, $\dot{Q}_{w}$, were compared to the electrical power supplied, $\dot{Q}_{e}$, via the heating wires, which were converted to heat because of the high resistance of the wires. The electrical power supplied was determined from the product of the currents, $I_{1}$, and $I_{2}$, through each of the two heating wires and the voltage drops, $\Delta V_{1}$ and $\Delta V_{2}$, over each wire as:

$$
\dot{Q}_{e}=I_{1} \Delta V_{1}+I_{2} \Delta V_{2}
$$

The electrical power, $\dot{Q}_{e}$, was continuously monitored and compared to the heat transfer rate, $\dot{Q}_{w}$, to the water, which should ideally be equal, as the test section was well insulated, to prevent heat loss to the environment as well as in an axial direction to the calming section and the outlet mixer. This monitoring was done with the determination of the energy balance error, $e b$, which should ideally be zero, or as close as possible to zero. This energy balance error, eb, was determined as:

$$
e b=\left|\frac{\dot{Q}_{e}-\dot{Q}_{w}}{\dot{Q}_{e}}\right|
$$


The heat fluxes, $\dot{q}_{w}$, on the inside of the test section to the water were determined from the heat transfer rate, $\dot{Q}_{w}$, to the water, and the inside surface area of the test section, along the heated length over which the heating wires were coiled. Therefore, the heat fluxes to the water were determined as:

$$
\dot{q}_{w}=\frac{\dot{Q}_{w}}{\pi D_{i} L_{h}}
$$

The heat transfer rate to the water was used to calculate the heat flux as it was judged to be more accurate than the electrical power supplied. This was because the electrical power supplied was always a little bit higher than the heat transfer rate to the water, which means that small heat losses occurred to the ambient air. This was also confirmed with the heat loss estimations when the insulation details were given.

With the heat fluxes and temperatures determined, the local heat transfer coefficients, $h(x)$, were determined at all the measuring stations as:

$$
h(x)=\frac{\dot{q}_{w}}{T_{s}(x)-T_{m}(x)}
$$

In the calculation of the heat transfer coefficients in Eq. 9, it was assumed that the temperatures on the inside of the tube were equal to the outside surface temperature, $T_{s}(x)$. This was justifiable as the thermal resistance of $1.67 \times 10^{-5} \mathrm{~K} / \mathrm{W}$ in the radial direction of the tube wall was very small, primarily because of the high thermal conductivity of the copper tube and the thin tube wall. One-dimensional conduction resistance calculations for the heat fluxes were applied, and indicated that the maximum temperature differences between the inside and outside of the tubes were less than $0.02{ }^{\circ} \mathrm{C}$, which were an order of magnitude smaller than the temperature measurement errors of the thermocouples on the outside surface. The local Nusselt numbers, $N u(x)$, were determined from the local heat transfer coefficients as: 


$$
N u(x)=\frac{h(x) D_{i}}{k_{w}(x)}
$$

and the local Colburn $j$-factor, $j(x)$, was determined from the local Nusselt numbers, $N u(x)$, local Reynolds numbers, $\operatorname{Re}(x)$, and local Prandtl numbers, $\operatorname{Pr}(x)$, at each station as:

$$
j(x)=\frac{N u(x)}{\operatorname{Re}(x) *[\operatorname{Pr}(x)]^{1 / 3}}
$$

The friction factors, $f$, were determined from the measured pressure drops, $\Delta P$, across the two pressure taps spaced apart at a distance of $L_{\Delta P}$, the bulk density in the fully developed section between the two pressure taps, $\rho_{b}$, the measured tube inner diameter, $D_{i}$, and the measured mass flow rates, $\dot{m}_{w}$, as:

$$
f=\frac{\Delta P \rho_{b} D_{i}^{5} \pi^{2}}{8 \dot{m}_{w}^{2} L_{\Delta P}}
$$

\section{Uncertainty analysis}

An uncertainty analysis was carried out as prescribed by Dunn [87], using the errors of the instrumentation (Table 2) and data reduction methodology (Section 3). The overall uncertainty of each of the instrumentation used during the experiments was calculated from the square root of the sum of the square of the bias and the precision. The bias was taken as the instrumentation accuracy provided by the manufacturers, while the precision was calculated from the standard deviation of a sample data containing 400 measuring points at a confidence level of 95\% [87].

It was found that the uncertainties of the minimum (400) and maximum (11 400) Reynolds numbers of the experiments were $1.1 \%$ and $0.29 \%$, while the uncertainties of the local Nusselt numbers at these Reynolds numbers were $2.2 \%$ and $3.6 \%$. The corresponding Colburn $j$-factor uncertainties were 4.83 and $3.23 \%$, while the uncertainties of the friction factors were $25 \%$ and $0.16 \%$ respectively. The friction factor uncertainties at low Reynolds numbers were high as the 
pressure drops were very small. However, the uncertainties decreased to less than $10 \%$ at Reynolds numbers higher than 2700.

Table 2. Ranges and measurement errors of instrumentation

\begin{tabular}{lll}
\hline Instrument & Range & Errors \\
\hline Flow meters & $0-108 \ell / \mathrm{h}$ & $0.054 \ell / \mathrm{h}(0.05 \%$ of range $)$ \\
CMF 010 & $0-2180 \ell / \mathrm{h}$ & $1.09 \ell / \mathrm{h}(0.05 \%$ of range $)$ \\
CMF 025 & $<150^{\circ} \mathrm{C}$ & $0.1^{\circ} \mathrm{C}$ \\
Thermocouples & $-100-250^{\circ} \mathrm{C}$ & $0.06^{\circ} \mathrm{C}$ \\
PT100s & $0-360 \mathrm{~V}$ & $0.02 \%$ of specified value \\
Current & $0-15 \mathrm{~A}$ & $0.02 \%$ of specified value \\
Voltage & $0-1.4 \mathrm{kPa}$ & $3.5 \mathrm{~Pa}(0.25 \%$ of range $)$ \\
Pressure transducers & $0-3.5 \mathrm{kPa}$ & $8.75 \mathrm{~Pa}(0.25 \%$ of range $)$ \\
\hline
\end{tabular}

\section{Experimental procedure and test matrix}

In general, most experiments commenced at the maximum mass flow rate of $0.15 \mathrm{~kg} / \mathrm{s}$. The electrical power supply was switched on and the required current and voltages were adjusted to obtain one of the required heat fluxes in Table 1. Sufficient time of about two hours was allowed for the system to reach a steady-state condition. Steady-state conditions were assumed once the standard deviation of temperatures and mass flow rate measurements were less than $0.02^{\circ} \mathrm{C}$ and $0.001 \mathrm{~kg} / \mathrm{s}$ respectively for a period of at least ten minutes.

Once steady-state conditions were achieved, 400 data points were logged of all the temperatures, mass flow rates, voltages, currents and pressure drops by the data acquisition system at a frequency of $20 \mathrm{~Hz}$. Experiments were conducted at different frequencies and over different time periods to ensure that the data is frequency and time independent. The 400 data 
points of each measuring station were averaged and were considered as one measurement for each station. At each measuring station, the average of the four thermocouples' measurements was used as the average temperature measurement at that station.

After logging a set of data, the mass flow rate of the water flowing in the loop was reduced by approximately $1 \%$. When these small changes were made in the mass flow rate, the subsequent steady-state condition was reached in about 14 to 17 minutes in the turbulent flow regime, 30 to 45 minutes in the transitional flow regime (the outlet temperature took a long time to stabilise) and 10 to 15 minutes in the laminar flow regime.

During experiments, the energy balance errors were also monitored. The maximum energy balance was $5 \%$ and was recorded during laminar flow conditions at the lowest mass flow rate when the wall temperature of the test section was at its highest. In the transitional flow regime, the maximum energy balance error was 3\%, and in the turbulent flow regime, the maximum energy balance error was less than $1 \%$.

The experimental matrix of experiments conducted for both the smooth tube and the tube with twisted tape inserts is summarised in Table 3. The smooth tube was tested at heat fluxes of 2, 3 and $4 \mathrm{~kW} / \mathrm{m}^{2}$. Three different twisted tape inserts with twist ratios of 3, 4 and 5 were then tested at heat fluxes of 2,3 and $4 \mathrm{~kW} / \mathrm{m}^{2}$. The matrix shows that, for the smooth tube experiments, measurements were taken at 219 different mass flow rates, while experiments were conducted at 646 different mass flow rates for the twisted tape inserts. The total number of experimental conditions investigated (different mass flow rates) on was 865 . 
Table 3. Summary of the experimental matrix of this study

\begin{tabular}{|c|c|c|c|}
\hline Tube condition & $\begin{array}{l}\text { Heat flux, } \dot{q} \\
\left(\mathrm{~kW} / \mathbf{m}^{2}\right)\end{array}$ & Twist ratio, $y$ & $\begin{array}{l}\text { Number of different } \\
\text { mass flow rates, } R e\end{array}$ \\
\hline \multirow[t]{3}{*}{ Smooth } & 2 & -- & 75 \\
\hline & 3 & -- & 76 \\
\hline & 4 & -- & 68 \\
\hline Subtotal & & -- & 219 \\
\hline \multirow[t]{9}{*}{ Twisted tape } & 2 & 3 & 79 \\
\hline & & 4 & 71 \\
\hline & & 5 & 71 \\
\hline & 3 & 3 & 78 \\
\hline & & 4 & 69 \\
\hline & & 5 & 70 \\
\hline & 4 & 3 & 76 \\
\hline & & 4 & 64 \\
\hline & & 5 & 68 \\
\hline Subtotal & & & 646 \\
\hline Total & & & 865 \\
\hline
\end{tabular}

\section{Validation with previous studies}

Prior to the commencement of the experiments with the twisted tape inserts, validation experiments were conducted on a smooth tube without any twisted tape inserts so that the experimental methodology, accuracy of measurements, repeatability, and data reduction methodology could be verified. As this study concentrated on the transitional flow regime, the experiments were conducted in the upper laminar flow regime, through the transitional flow 
regime, and into the turbulent flow regime. Before the results could be compared to literature studies, it was also important to determine if the flow was fully developed; not only for the smooth tube experiments, but also for the experiments with the tubes with twisted tape inserts. For the smooth tube, the flow should theoretically be fully developed at a length of $15.3 \mathrm{~m}$ (using the well-known equation of, $L_{t h}=0.05 \operatorname{RePr} D_{i}$, for forced convection at a Reynolds number of 2300 and a Prandtl number of 7). Thus, theoretically if only forced convection existed, fully thermally developed flow should not occur as the test section is $5.27 \mathrm{~m}$ in length.

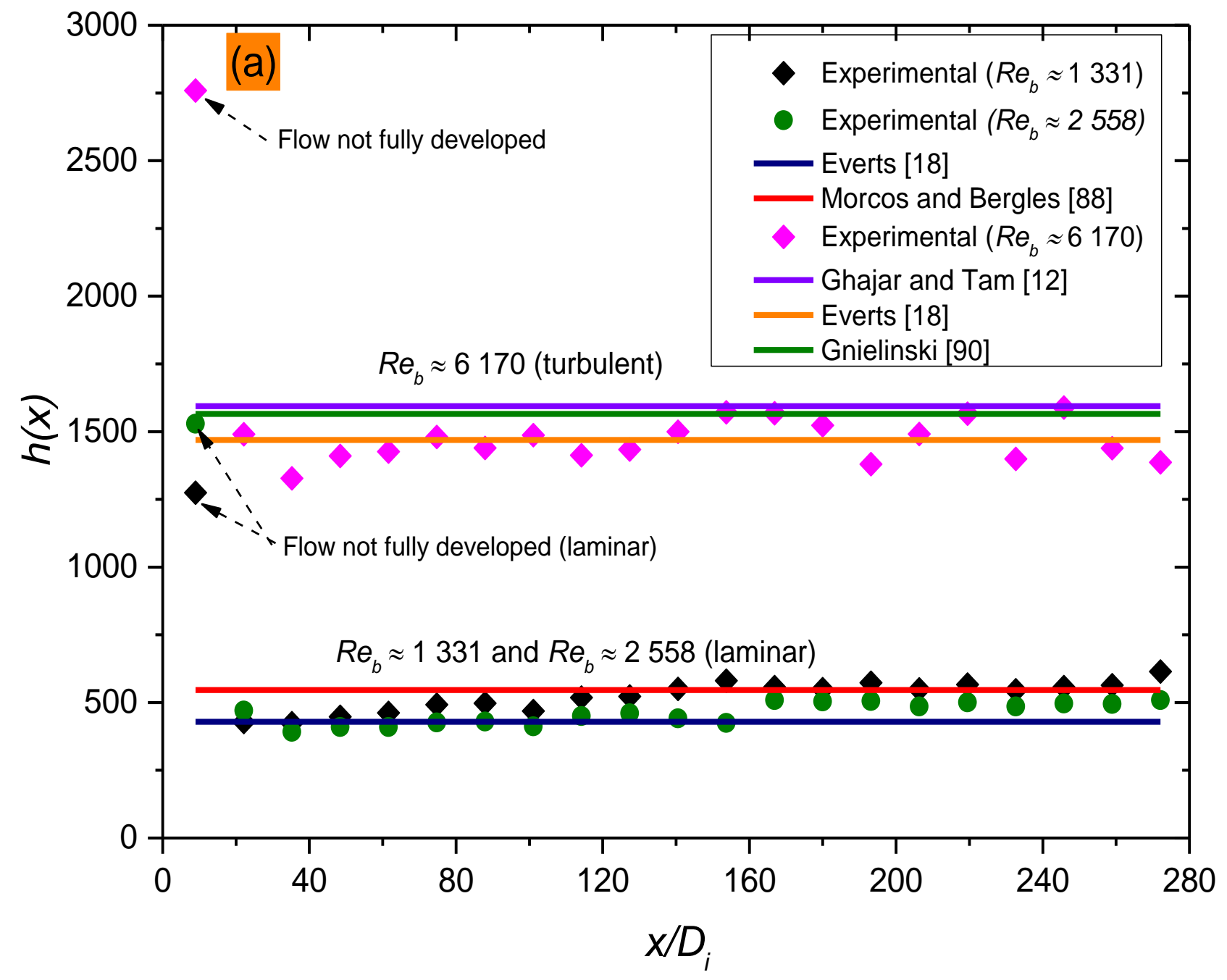

Fig. 4a. Comparison of local heat transfer coefficients with literature for the smooth tube. The results were for three bulk Reynolds numbers of 1331,2558 (laminar) and 6170 (turbulent) at a heat flux of $2 \mathrm{~kW} / \mathrm{m}^{2}$. 


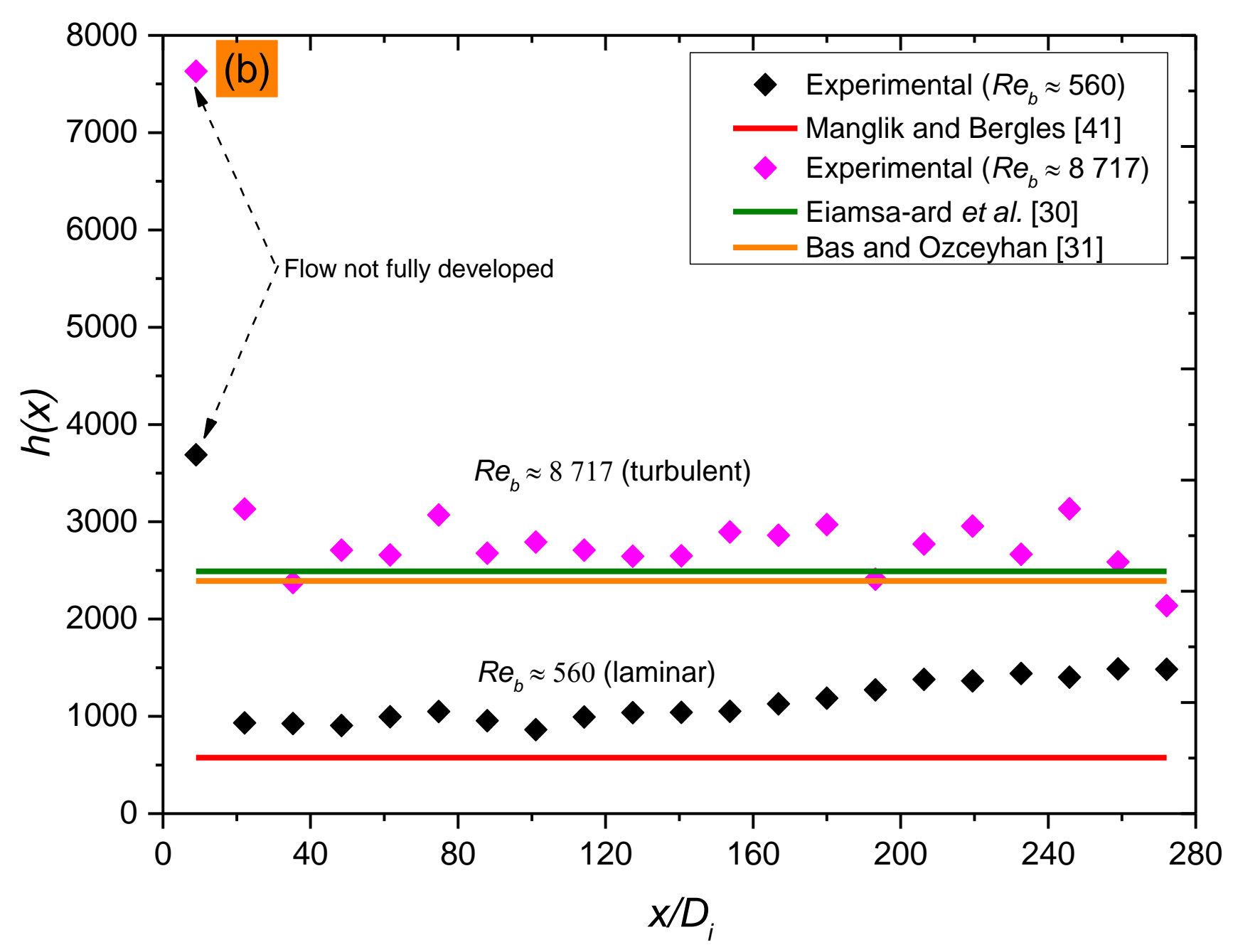

Fig. 4b. Comparison of local heat transfer coefficients of the tube with a twisted tape with literature, at two bulk Reynolds numbers of 560 (laminar) and 8717 (turbulent). The twist ratio, $y$, of the twisted tape insert was 5 and the heat flux was $2 \mathrm{~kW} / \mathrm{m}^{2}$.

In Fig. 4, the local heat transfer coefficient results are given for the smooth tube (Fig. 4a) and for a tube with a twisted tape insert (Fig. 4b) as a function of a dimensionless tube length-todiameter ratio at a heat flux of $2 \mathrm{~kW} / \mathrm{m}^{2}$. In Fig. $4 \mathrm{a}$, results are given for the smooth tube at two laminar bulk Reynolds numbers of 1331 and 2558 (close to the start of transition as indirectly indicated later in Fig. 8) and at a turbulent bulk Reynolds number of 6170. 
Several observations were made when the results were compared to literature. At a bulk Reynolds number of 1331 in the laminar flow regime, the local heat transfer coefficients of this study compared well with the correlations of Everts [18]. The average deviation was 17\%. It was also compared with the equation of Morcos and Bergles [88], which predicted on average 6\% lower heat transfer coefficients than were determined from this study. The results also showed that the heat transfer coefficients remained constant in an axial direction, except at the first measuring station. It can therefore be assumed that the flow was fully developed, except for the first measuring station.

The additional laminar experiments at a bulk Reynolds number of 2558 were included to show that all the local heat transfer coefficients in the laminar flow regime indicated that the flow was fully developed, except at the first measuring station. The reason why the flow was so quickly fully developed was because the flow with heating was not in the forced convection flow regime, but in the mixed laminar flow regime [12]. In this regime, secondary flow occurs, which ensures that fully developed flow develops sooner. This was confirmed with surface temperature measurements that showed that the temperatures at the top of the tube were not equal to the temperatures at the bottom of the tube. The average ratio of these temperatures for a Reynolds number of 2558 was 0.9 . The observations that the flow was fully developed along the test section length was observed for all the experimental conditions in Table 1.

In turbulent flow, at a Reynolds number of 6 170, again except for the first measuring station, $x / D_{i}=8.9$, all the other local heat transfer coefficients were independent of axial tube location. This was to be expected as the general guideline is that fully developed turbulent flow occurs after 10 diameters from the tube inlet $[8,89]$. All the local heat transfer coefficients were within $\pm 6 \%$ of the average heat transfer coefficient. Furthermore, the results compared well with the 
measurements of Ghajar and Tam [12], Everts [18] and Gnielinski [90]. The average deviations with these studies were $9 \%, 1 \%$ and $7 \%$ respectively.

Similar trends were found in the experiments with the tubes with twisted tape inserts, as shown in Fig. 4b. The results shown are for a tube with a twisted tape insert, with a twist ratio of 5. In the laminar flow regime at the bulk Reynolds number of 560, except at the first measuring station, the values of the heat transfer coefficients were constant and not a function of the axial length. Towards the end of the test section, the local heat transfer coefficients increased gradually. This increase is associated with the loss effect at the exit of the test section. A similar trend of exit losses when using a tube with a twisted tape insert was also reported in the work carried out by Chang, et al. [37], Chang, et al. [38] and Chang and Zhen [91]. The average value of the heat transfer coefficient was $1145 \mathrm{~W} / \mathrm{m}^{2} \mathrm{~K}$, and the heat transfer coefficients of all the stations, excluding the first one, were within an absolute deviation of $14 \%$ of this value. Furthermore, the results of this study were higher than the correlation of Manglik and Bergles [41]. It was therefore assumed from the results in the laminar flow regime that the heat transfer coefficients at all the measuring stations were fully developed, except at the first measuring station.

In the turbulent flow regime, at a bulk Reynolds number of 8717 (Fig. 4b), the heat transfer coefficients were also generally constant and independent on the axial tube length. The only exception, again, was the first measuring station. The average heat transfer coefficient was $2741 \mathrm{~W} / \mathrm{m}^{2} \mathrm{~K}$, and the heat transfer coefficients of all stations were within $10 \%$ of this value. Therefore, it was assumed that the heat transfer coefficients of all the stations, except the first one, were fully developed. Furthermore, the results were within $10 \%$ of the equation of Eiamsaard, et al. [30] and within 13\% of the equation of Bas and Ozceyhan [31]. 
In general, the local heat transfer coefficients in Fig. 4 (as well as at the other experimental conditions listed in Table 1) showed that the flow was thermally fully developed. The exceptions, for both laminar and turbulent flow, were at the first measuring station where the flow was developing.

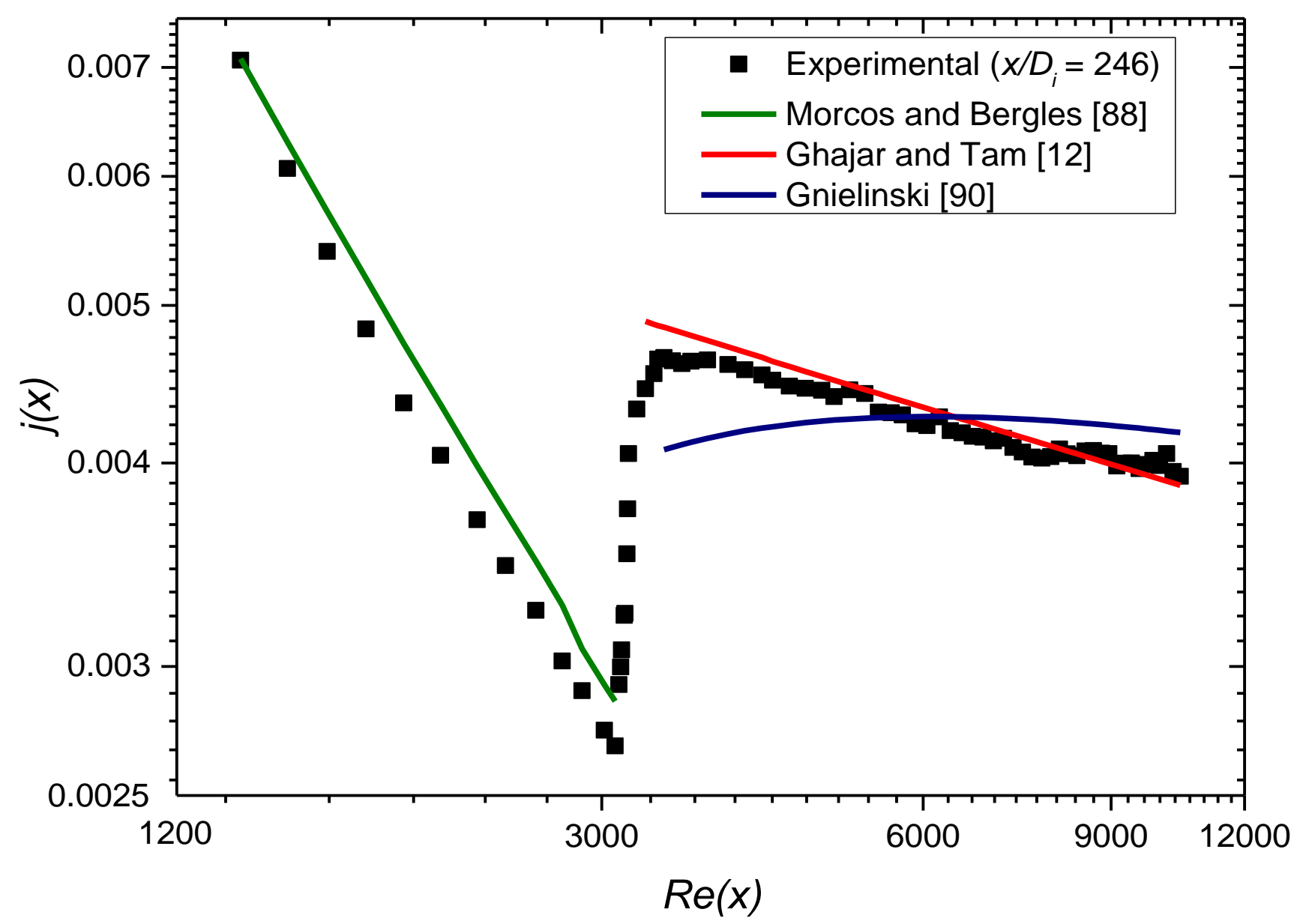

Fig. 5. Comparison of the Colburn $j$-factors as a function of Reynolds numbers at $x / D_{i}=246$ and a heat flux of $2 \mathrm{~kW} / \mathrm{m}^{2}$, with literature.

In Fig. 5, the Colburn $j$-factors as a function of Reynolds numbers at $x / D_{i}=246$ and a heat flux of $2 \mathrm{~kW} / \mathrm{m}^{2}$ are presented over the Reynolds number range of $1377-10449$. In general, the results compared well with literature. The results of the Colburn $j$-factors in the laminar flow 
regime were compared to the results of Morcos and Bergles [88] with respective average deviations of $7 \%$. The transition occurred at Reynolds numbers between $3053-3331$. In the turbulent flow regime, the Colburn $j$-factor results were compared to those of Gnielinski [90]. These equations predicted the present data well in the turbulent flow regime, with minimum and maximum deviations of $6 \%$ and $12 \%$ respectively. A maximum deviation of $5 \%$ was obtained with the correlation of Ghajar and Tam [12].

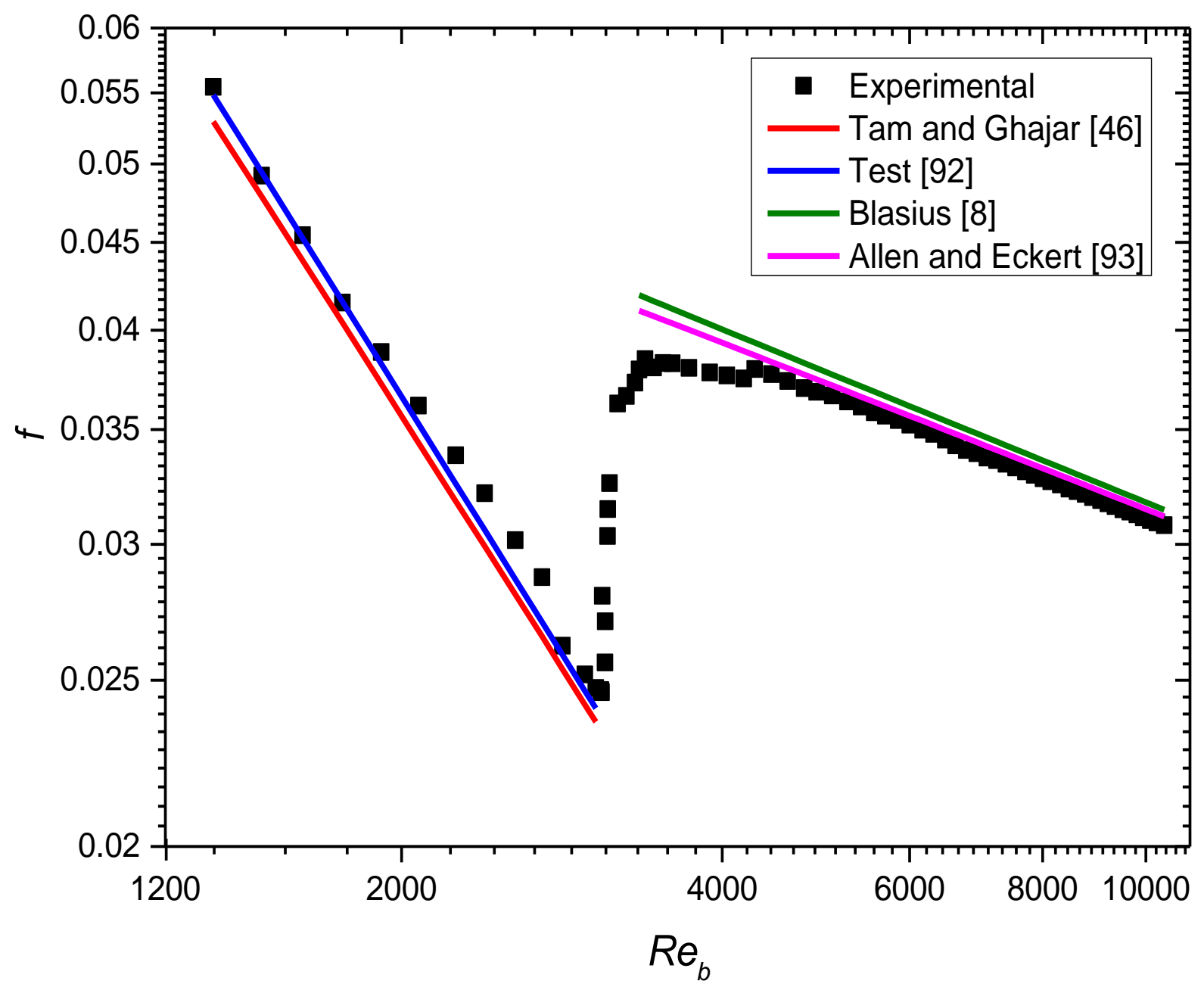

Fig. 6. Comparison of the smooth tube diabatic friction factors against bulk Reynolds numbers at a heat flux of $2 \mathrm{~kW} / \mathrm{m}^{2}$, with literature. 
In Fig. 6, the diabatic friction factors against the bulk Reynolds numbers of the smooth tube at a heat flux of $2 \mathrm{~kW} / \mathrm{m}^{2}$ are shown over the fully developed pressure drop length of $2.45 \mathrm{~m}$. The friction factor results in the laminar flow regime were compared to Tam and Ghajar [46] and Test [92] with a maximum deviation of $\pm 5 \%$. The diabatic friction factors in the turbulent flow regime were compared to those of Blasius contained in Cengel and Ghajar [8] and Allen and Eckert [93], and most of the data were predicted with a deviation of $\pm 5 \%$.

Although only results of $2 \mathrm{~kW} / \mathrm{m}^{2}$ were shown in this section, similar results were found for heat fluxes of 3 and $4 \mathrm{~kW} / \mathrm{m}^{2}$, It has been found that when the smooth tube and twisted tape measurements of this section were repeated 14 months later, after the completion of the twisted tape inserts in section 7, the results in Figs. 4 to 6 compared with errors of less than 1\%. It was therefore concluded that the results were repeatable and that negligible drift occurred in all instrumentation and/or measurements that were conducted in this study over the period of experimentation.

\section{Results and discussion}

The general conclusion that was reached from the results in Section 6 was that the results for both the smooth tube and the tube with the twisted tape inserts represented thermally fully developed flow. The exceptions were the results for the first measuring station, which were in the developing flow regime. Therefore, the results can be presented as the average of stations 2 to 21 , or alternatively at one specific station. The latter was used, and therefore all the results related to temperature measurements, Colburn $j$-factors and Reynolds number calculations in this section were specifically the local values from the measurements at station 19 , where $x / D_{i}=$ 246. It has also been found that, if the bulk temperature calculation, as shown in Eq. (2), is 
adjusted to exclude/include the distance from the first measuring station, the difference between the fully developed local and bulk Reynolds numbers were negligible.

The average or bulk results (Colburn $j$-factors, Nusselt numbers, Reynolds numbers) were also compared to the local values at station 19, and it was found that the results deviated by less than $3 \%$. The friction factors were, of course, not a local value, as it was the pressure drop over the last part of the test section (Figs. 1 and 3), between approximately stations 11 and 21 . These results were presented as a function of the bulk Reynolds number. There was a negligible difference between the bulk Reynolds number based on the temperature at the centre of the two pressure taps at $x=3.796 \mathrm{~m}$ and the bulk Reynolds number based on the mean temperature at the centre of the tube at $x=2.635 \mathrm{~m}$.

\subsection{Transition}

The boundaries of the start and end of transition were identified using two methods: a standard deviation method and a linear line method.

\subsubsection{Standard deviation method}

With the standard deviation method, the standard deviation, $\sigma$, of the 400 surface temperature measurements as a function of time were evaluated and compared as shown in Figs. 7(a) to 7(f). These evaluations were conducted for 20 of the 21 stations (the first measuring station was excluded). As the Reynolds number during experiments was decreased from the maximum to the minimum Reynolds number, it was found that three flow regimes could be identified. In the turbulent flow regime, the standard deviations of the measurements were all $0.1^{\circ} \mathrm{C}$ (which corresponds to the uncertainty of temperature measurements of this study). It then increased to $0.2^{\circ} \mathrm{C}$ or higher in the transitional flow regime, and reduced to $0.1^{\circ} \mathrm{C}$ in the laminar flow regime. In Fig. 7, the results are shown for the smooth tube with Reynolds numbers 1377 (Fig. 7a 
laminar flow), 2755 (Fig. 7b close to the end of the laminar flow regime), 3173 (Fig. 7c in the beginning of the transitional flow regime), 3179 (Fig. $7 \mathrm{~d}$ close to the end of the transitional flow regime), 3279 (Fig. 7e in probably the low-Reynolds-number end of the transition) and 4497 (Fig. 7f turbulent flow). The low-Reynolds-number end results could be distinguished from the transitional and turbulent results by the change in frequency. In the transitional flow regime, the average frequency, $f_{r}$, of the fluctuations was approximately $1 / 20 \mathrm{~Hz}$ (Figs. $7 \mathrm{c}$ and $7 \mathrm{~d}$ ) with a standard deviation temperature of $0.2^{\circ} \mathrm{C}$, while in the low-Reynolds-number end the frequency, this changed to $1 / 10 \mathrm{~Hz}$ (Fig. 7e) with a standard deviation temperature of $0.1{ }^{\circ} \mathrm{C}$.

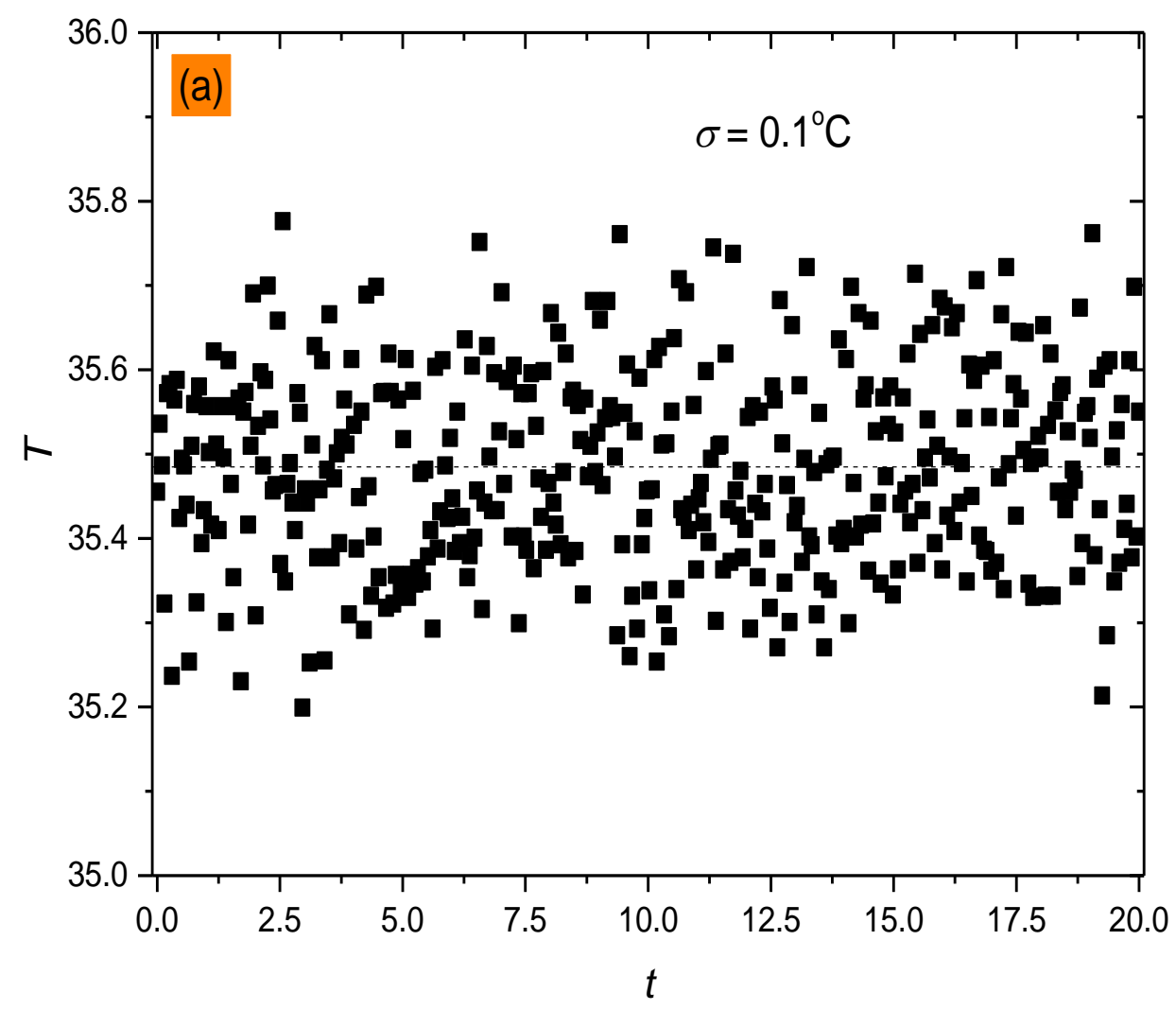



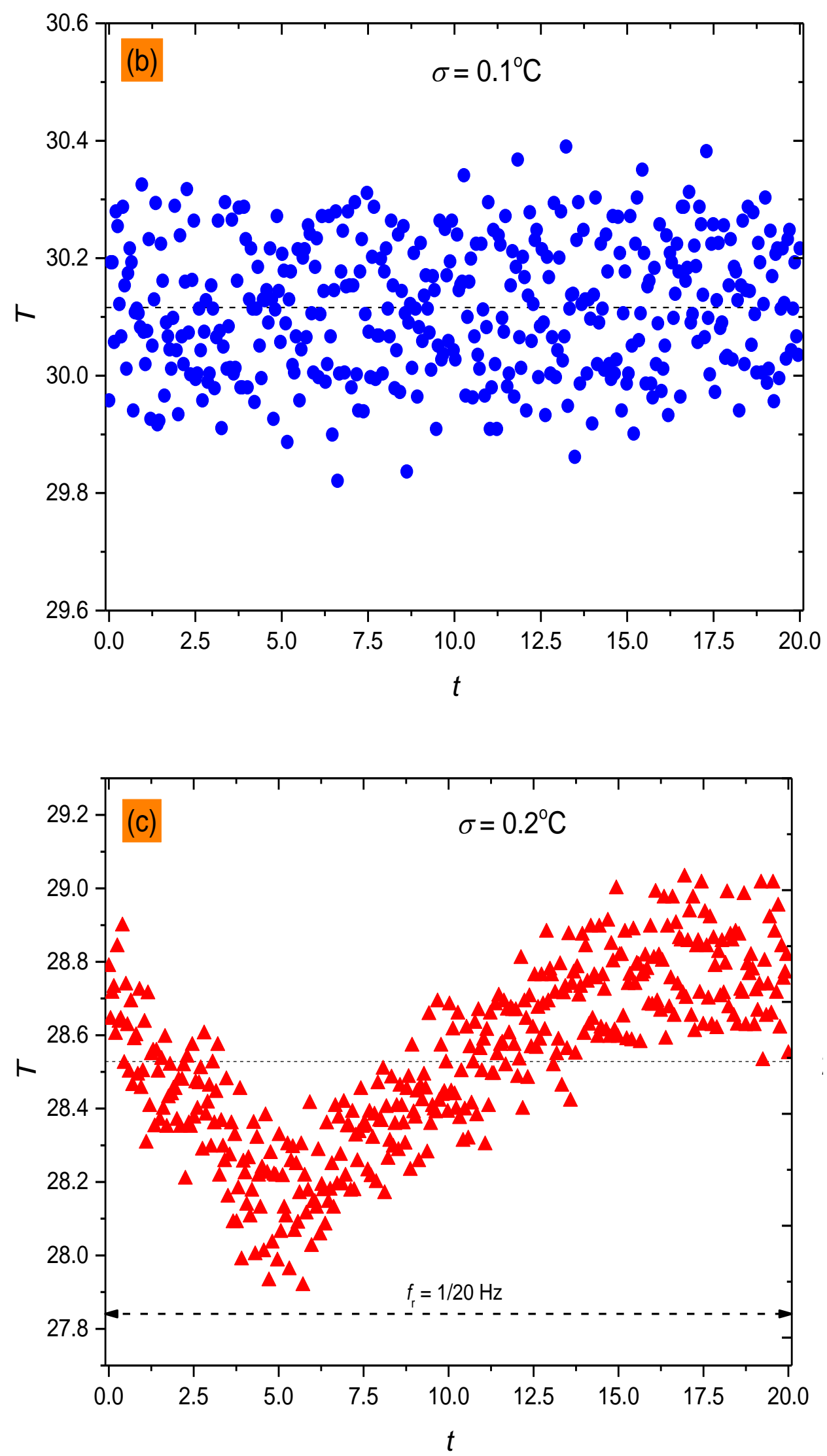


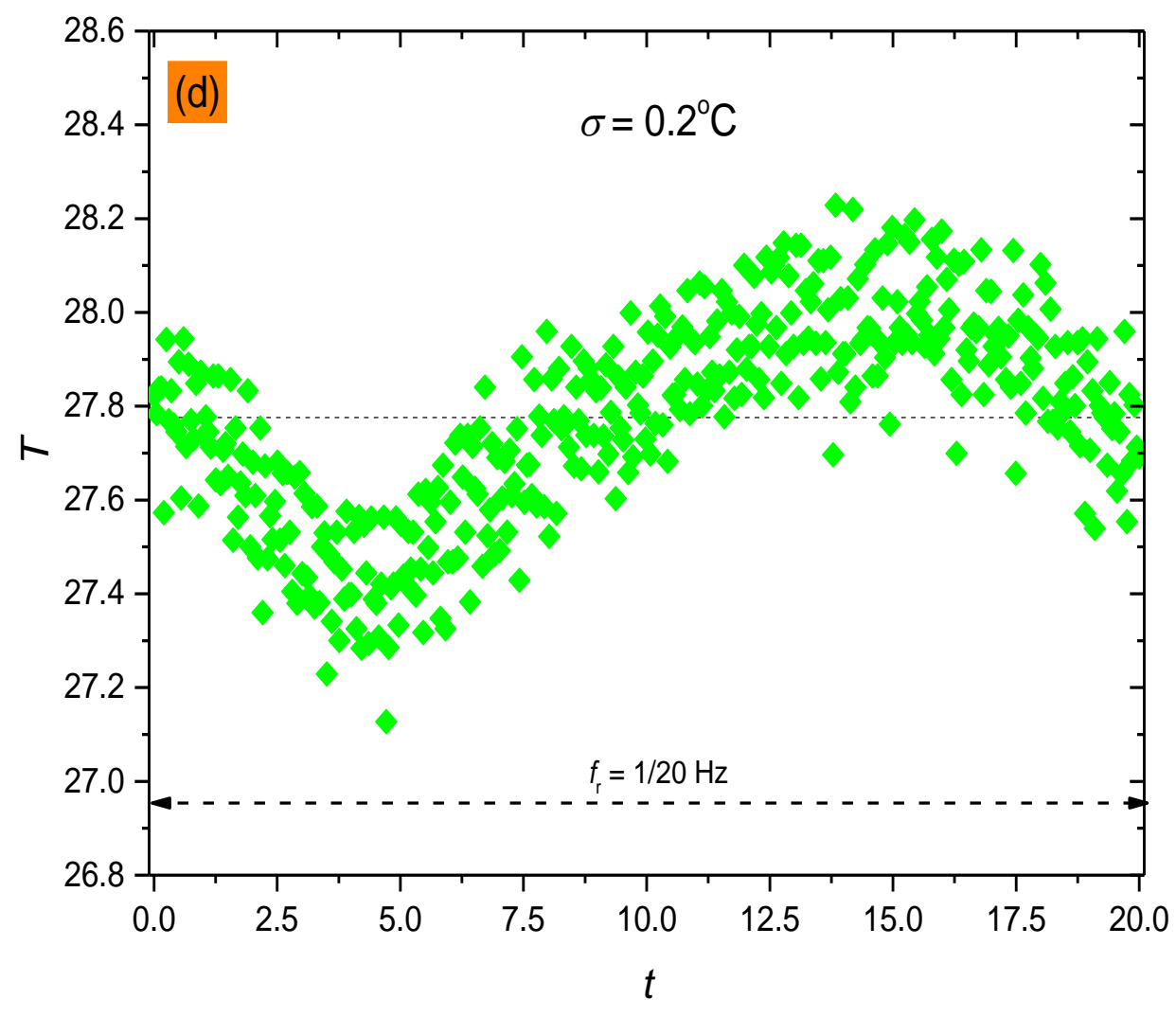

7.1.2

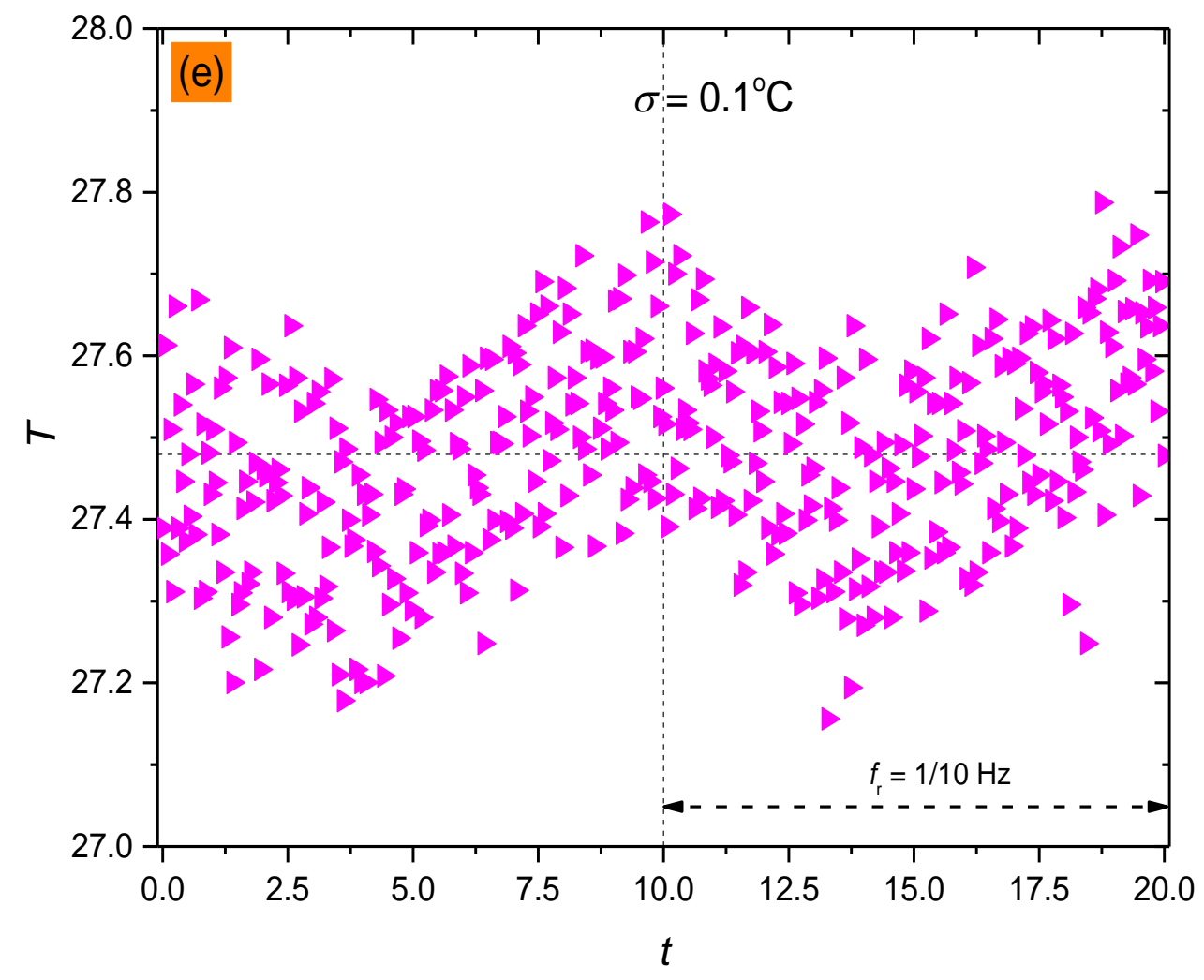




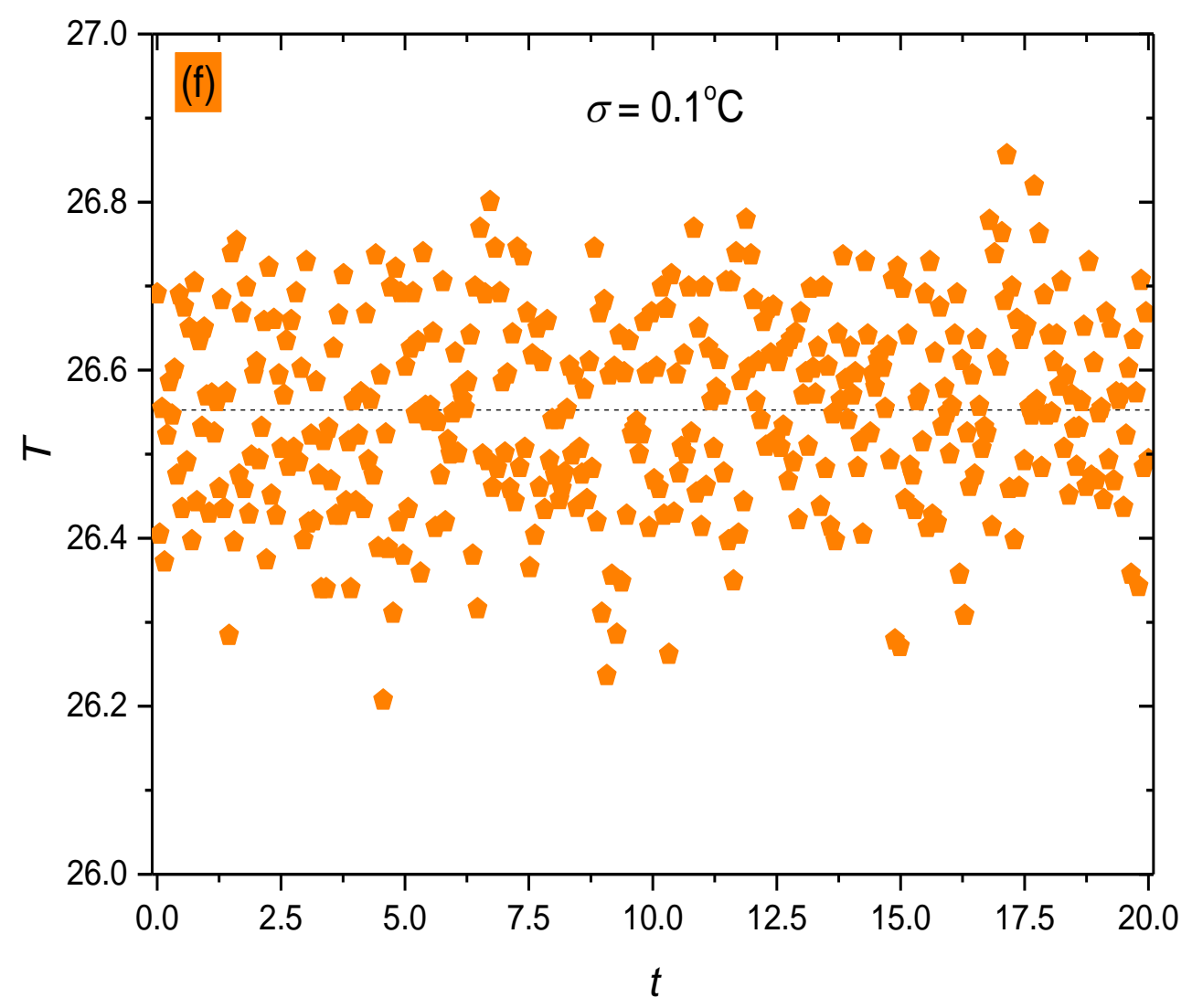

Fig. 7. Deviation of the local surface temperatures in the smooth tube against time at $x / D_{i}=246$, a heat flux of 2 kWm² and Reynolds numbers of: (a) 1 377; (b) 2 755; (c) 3 173; (d) 3 179; (e) 3297 and (f) 4497. The labels (a) to (f) correspond to the labels in Fig. 8.

\subsubsection{Linear line method}

From the smooth tube results, it was found that the transitional flow regime can be well described with three linear curve fits on a log-log scale, as illustrated in Fig. 8. The results that could be confidently identified as turbulent are shown with the lines connecting the two "T" markers in Fig. 8. These results were for Reynolds numbers larger than 4000 . The results close to the transitional flow regime were not taken into consideration. A linear-line curve fit was then constructed through the laminar points, indicated by the two "L" markers. These values were conservatively identified as all the laminar results with Reynolds numbers smaller than 3000. 
The remaining line was constructed with a curve fit from Reynolds numbers 3114 to 3250 , that connected the two "R" markers. Care was taken not to select data close to the points where transition started and ended.

The Reynolds numbers at the two intersections of the "R-R" transition line, with the "L-L" laminar line and the "T-T" turbulent line, were identified for the purposes of this study as the beginning, $R e_{c r, b}$, and end, $R e_{c r, e}$, of transition. The beginning of transition in Fig. 8 was at $R e_{c r, b}=3053$ and the end of transition was at $R e_{c r, e}=3331$. The width of transition was defined as the difference between the Reynolds numbers at the end and at the beginning of transition, thus $T F R=R e_{c r, e}-R e_{c r, b}$.

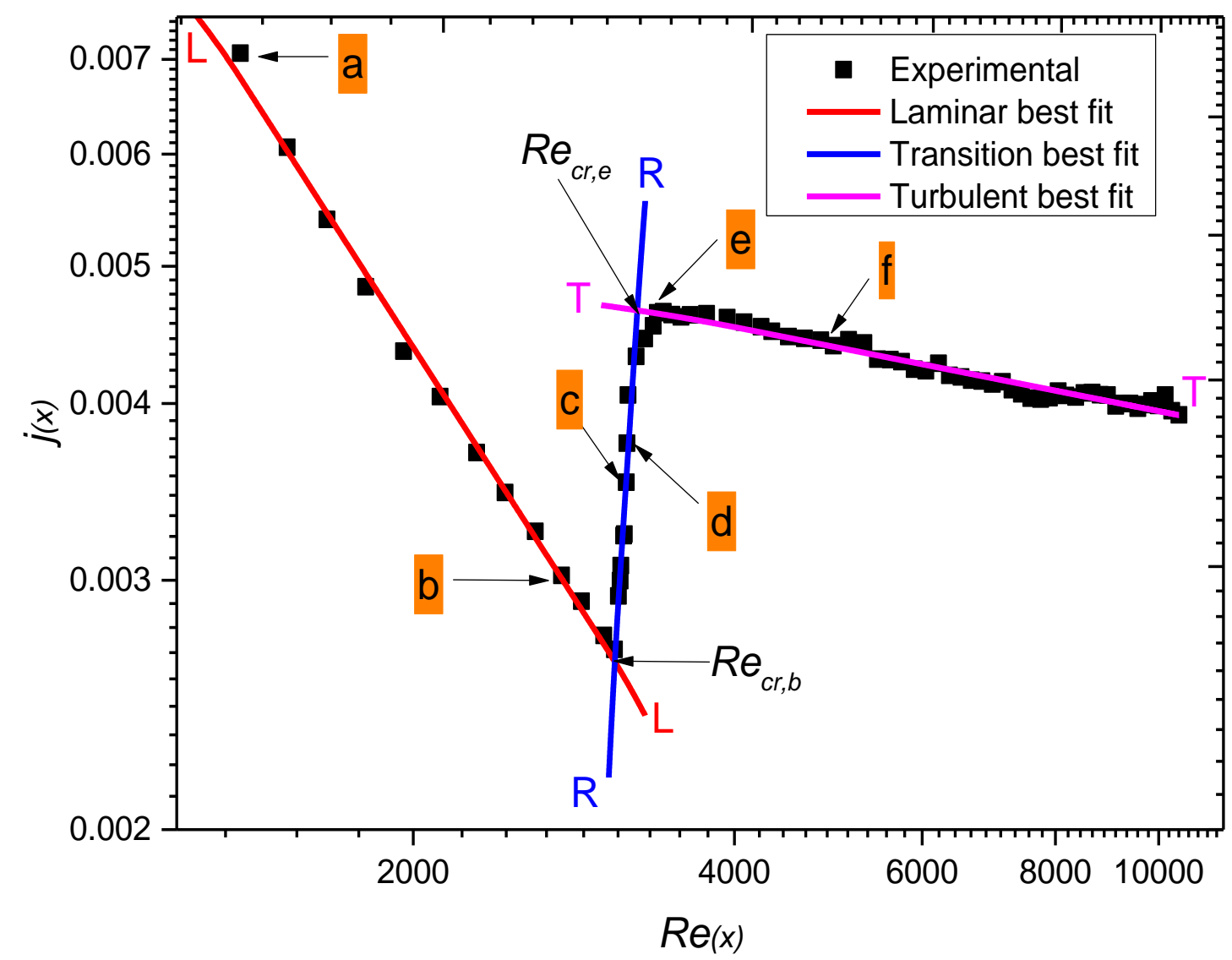

Fig. 8. Variation of the local Colburn $j$-factors with local Reynolds numbers at a heat flux of $2 \mathrm{~kW} / \mathrm{m}^{2}$ in the smooth circular tube at $\boldsymbol{x} / \boldsymbol{D}_{i}=\mathbf{2 4 6}$. 


\subsubsection{Twisted tapes}

The same approach was also used for the tubes with twisted tape inserts, as shown in Fig. 9 for the standard deviation method and Fig. 10 for the linear line method. The results are for a tube with a twisted tape insert with a twist ratio of 5 and a heat flux of $2 \mathrm{~kW} / \mathrm{m}^{2}$. In the turbulent flow regime, the "T-T" line was constructed for Reynolds numbers larger than 2000 . In the laminar flow regime, the "L-L" line was constructed for Reynolds numbers lower than 1000. The transitional flow regime line, "R-R", was constructed for Reynolds numbers between 1098 and 1 289. The beginning of the transitional flow regime in Fig. 10 was at $R e_{c r, b}=1023$, and the end of transition was at $R e_{c r, e}=1604$. A summary of the transitional flow regimes for the smooth tube, as well as the twisted tape inserts given in Table 4.

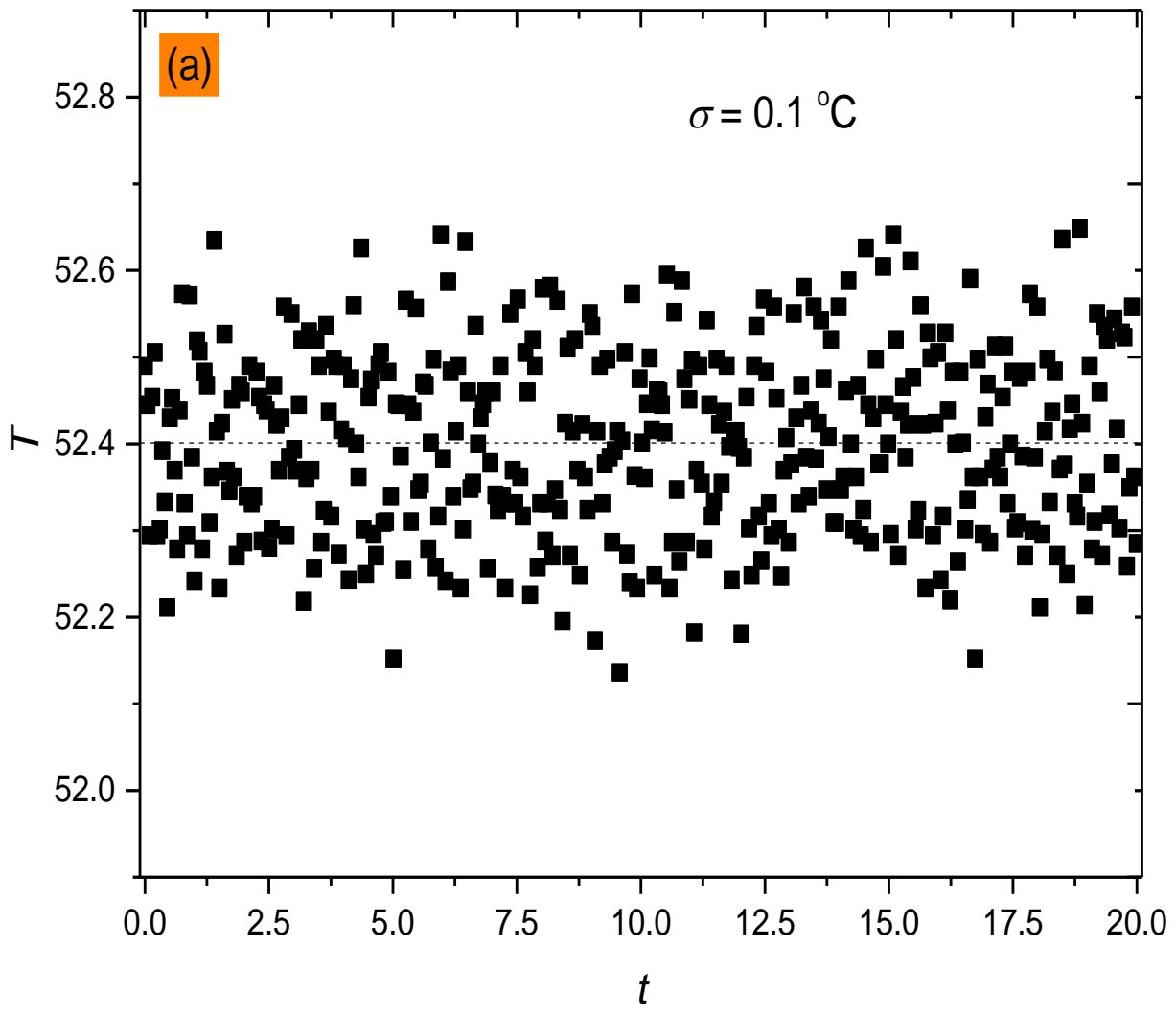



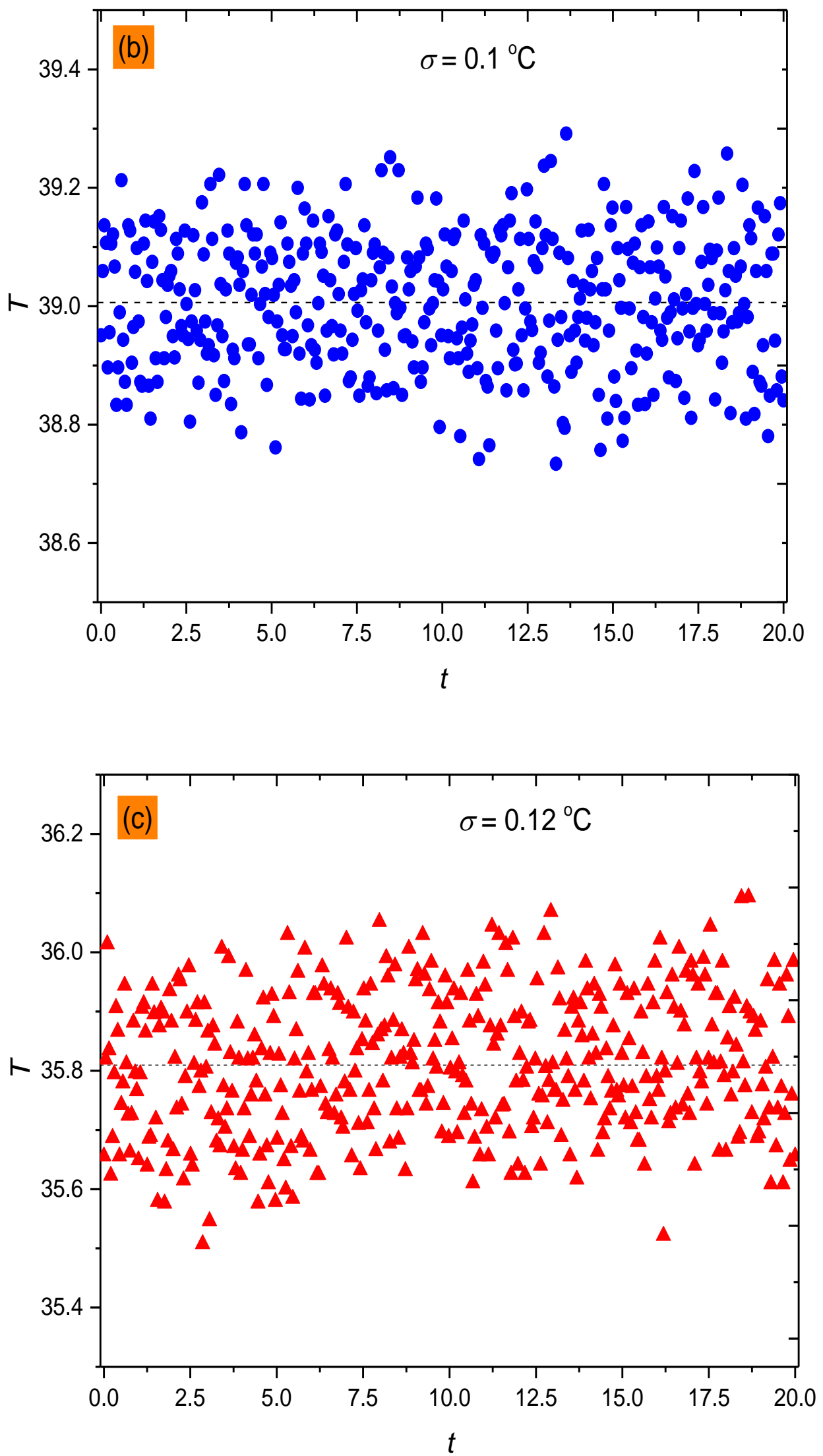

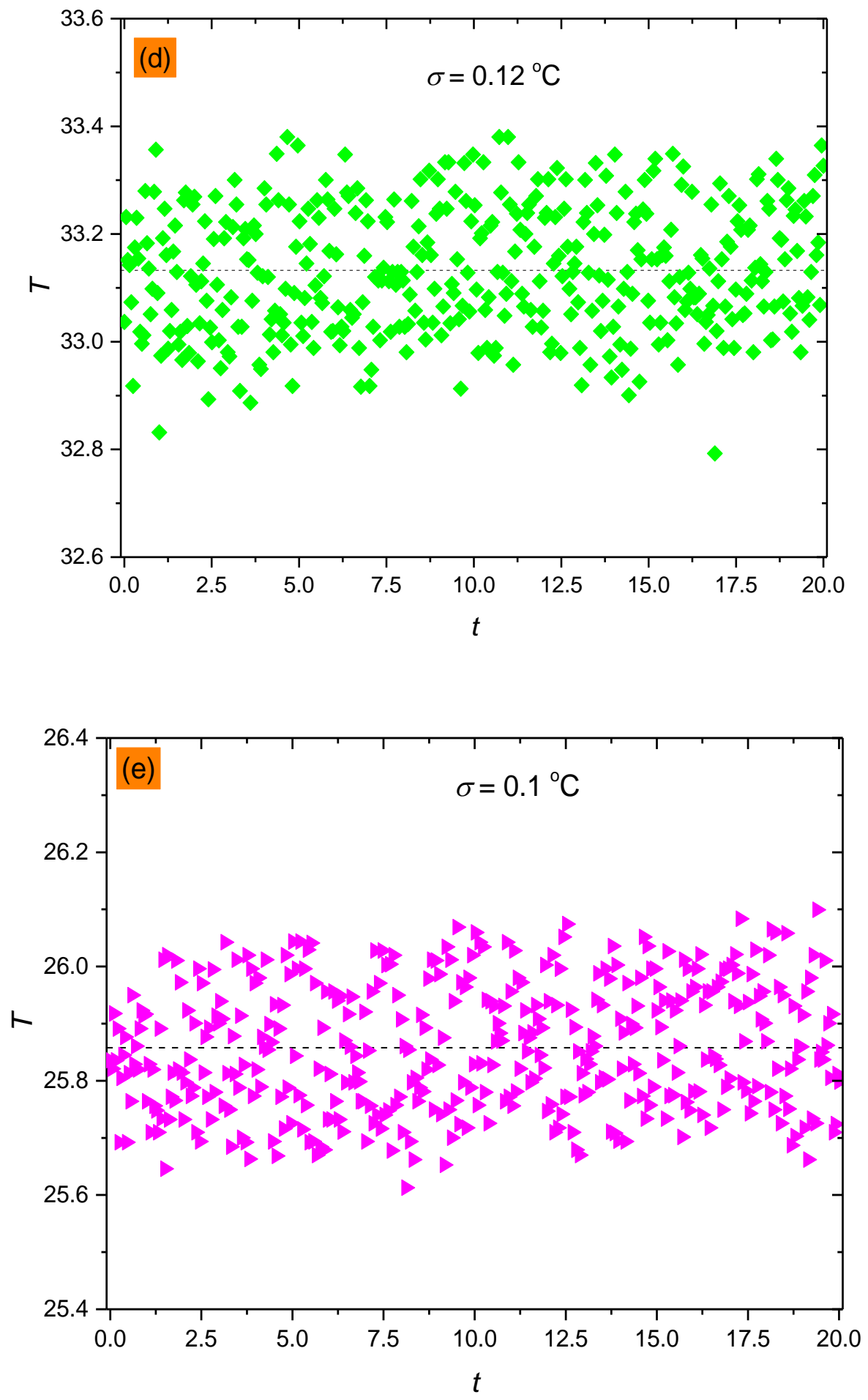

Fig. 9. Deviation of the local surface temperatures in the smooth circular tube with twisted tape insert with a twist ratio of $y=5$ against time at $x / D_{i}=246$, a heat flux of $2 \mathrm{~kW} / \mathrm{m}^{2}$, and Reynolds numbers of: (a) 610 ; (b) 995; (c) 1 193; (d) 1461 and (e) 4 492. The labels (a) to (e) correspond to the labels in Fig. 10. 


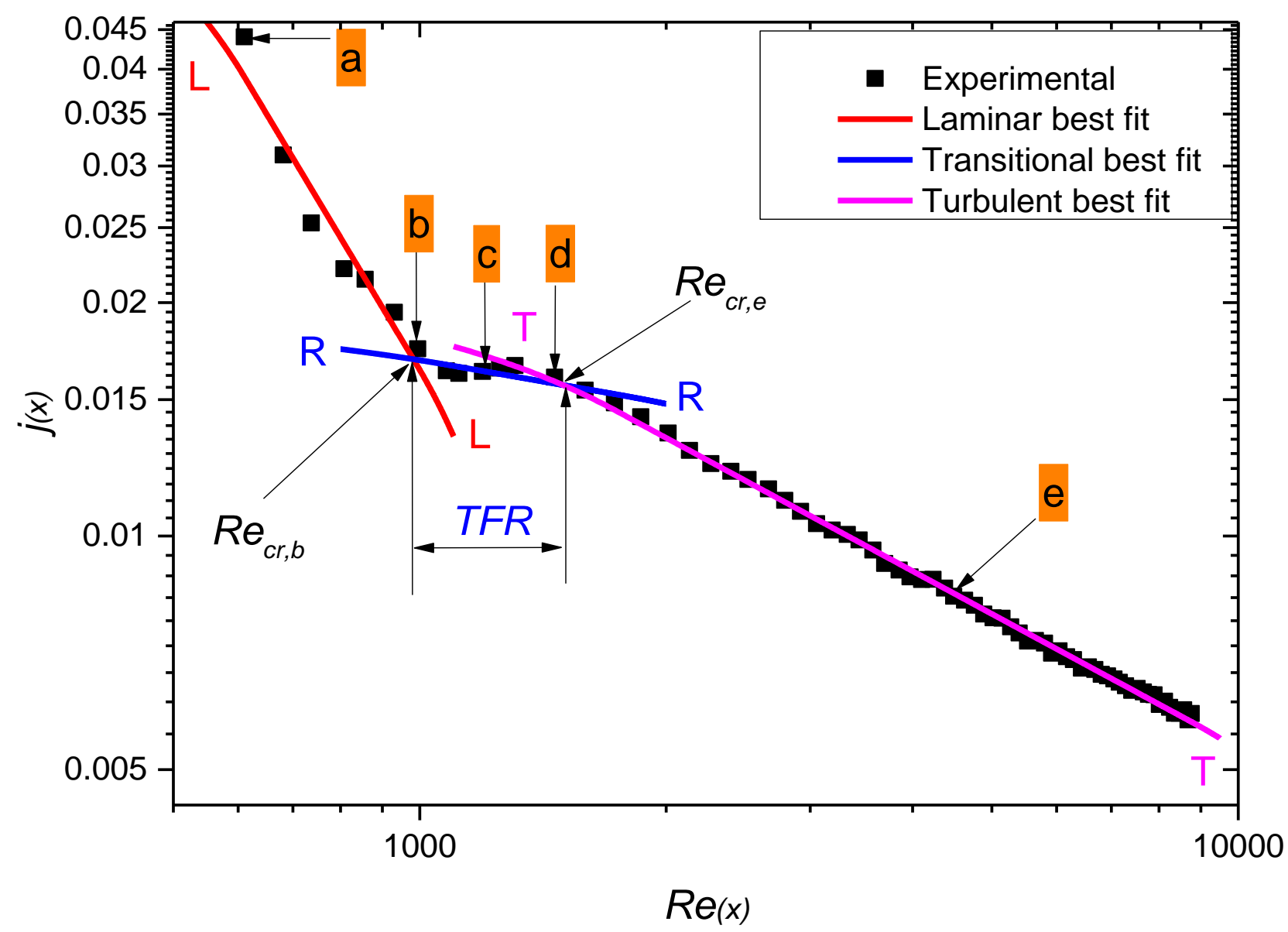

Fig. 10. Local Colburn $j$-factors as a function of local Reynolds numbers at $\boldsymbol{x} / \boldsymbol{D}_{\boldsymbol{i}}=\mathbf{2 4 6}$ and a heat flux of $2 \mathrm{~kW} / \mathrm{m}^{2}$, for a tube with a twisted tape insert with a twist ratio of $\boldsymbol{y}=\mathbf{5}$.

Table 4. Ranges of transitional flow regime Reynolds numbers of the Colburn $j$-factors with the smooth tube and twisted tape inserts at different heat flux boundary conditions

\begin{tabular}{|c|c|c|c|c|c|c|c|c|c|c|c|c|}
\hline \multirow{3}{*}{$\begin{array}{l}\text { Heat } \\
\text { fluxes }(\dot{q}) \\
{\left[\mathrm{kW} / \mathrm{m}^{2}\right]}\end{array}$} & \multicolumn{3}{|c|}{ Smooth } & \multicolumn{9}{|c|}{ Twist ratios } \\
\hline & \multirow[b]{2}{*}{$\boldsymbol{R} \boldsymbol{e}_{c r, b}$} & \multirow[b]{2}{*}{$\boldsymbol{R} \boldsymbol{e}_{c r, e}$} & \multirow[b]{2}{*}{$T F R$} & \multicolumn{3}{|c|}{$y=3$} & \multicolumn{3}{|c|}{$y=4$} & \multicolumn{3}{|c|}{$y=5$} \\
\hline & & & & $R e_{c r, b}$ & $\boldsymbol{R} \boldsymbol{e}_{c r, e}$ & TFR & $\boldsymbol{R} \boldsymbol{e}_{c r, b}$ & $\boldsymbol{R} \boldsymbol{e}_{c r, e}$ & TFR & $R e_{c r, b}$ & $\boldsymbol{R} e_{c r, e}$ & TFR \\
\hline 2 & 3053 & 3331 & 278 & 593 & 1125 & 532 & 669 & 1027 & 358 & 1023 & 1604 & 581 \\
\hline 3 & 3164 & 3452 & 288 & 819 & 1274 & 455 & 951 & 1418 & 467 & 1108 & 1683 & 575 \\
\hline 4 & 3266 & 3565 & 299 & 1093 & 1404 & 311 & 1172 & 1524 & 352 & 1278 & 1775 & 497 \\
\hline
\end{tabular}


Although the two methods used to identify the transitional flow regimes, relied in some cases on subjective decisions (which data to include and/or exclude in a flow regime), it was found that reasonable results could be obtained if the two methods were used complementary to each other, and in some cases by iterating between the two methods. However, it was found that the linear line method was quicker to implement than the standard deviation method, especially if enough data points were available in all three the flow regimes (laminar, transitional and turbulent). For some experiments at low mass flow rates (and thus low Reynolds numbers), the outlet temperatures became too high, which resulted in a very limited number of experimental data points in the laminar flow regime. In these cases, the transitional to turbulent flow points could be described well, but not the laminar to transitional flow points. In some of these cases, only one or two laminar data points could be identified, with Reynolds numbers of approximately 500.

\subsection{Heat transfer}

For simplicity, the following correlations were selected for the curve fits of the Colburn $j$ factors that represent the non-dimensional heat transfer coefficients for the smooth tube results:

$$
j(x)=d[\operatorname{Re}(x)]^{c}\left(\frac{\mu_{b}}{\mu_{s}}\right)^{0.14}
$$

with $d$ being the $y$-axis intercept and $c$ being the slope. It was found that inserting the term $\left(\mu_{b} / \mu_{s}\right)^{0.14}$ gave better results, although the viscosity ratios only varied in the range of $1.01 \leq \mu_{b} / \mu_{s} \leq 1.09$. The Colburn $j$-factors, Reynolds numbers and viscosities were all obtained using the local values per station. To reflect the influence of the twisted tape inserts, as a function of twist ratio, $y$, Eq. (13) was adapted for twisted tapes to: 


$$
j(x)=a y^{b}[\operatorname{Re}(x)]^{c}\left(\frac{\mu_{b}}{\mu_{s}}\right)^{0.14}
$$

with $d=a y^{b}$. It was also found that a value of $b=0.3$ gave acceptable results for all the experiments that were conducted.

The values of the variables $a, c$ and $d$ were determined for each case and are summarized in Table 5. The average and maximum deviations of each curve fit with the experimental data, using the values of $R e_{c r, b}$ and $R e_{c r, e}$, are also included. Thus, for laminar results, all the data with Reynolds numbers smaller than $R e_{c r, b}$ was used. To further distinguish the variables in the table, the $a, c$ and $d$ values were used together with the subscripts of $L, R$ and $T$ to identify the laminar, transitional, and turbulent flow regimes respectively. The $T F R$ values were also given in the table.

For the smooth tube (Fig. 8), the resulting equation for laminar flow is:

$$
j_{L}(x)=24.5[\operatorname{Re}(x)]^{-1.23}\left(\frac{\mu_{b}}{\mu_{s}}\right)^{0.14}
$$

The transitional flow regime is described by:

$$
j_{R}(x)=4.62 x 10^{-25}[\operatorname{Re}(x)]^{6.25}\left(\frac{\mu_{b}}{\mu_{s}}\right)^{0.14}
$$

The turbulent flow regime is described by:

$$
j_{T}(x)=0.016[\operatorname{Re}(x)]^{-0.152}\left(\frac{\mu_{b}}{\mu_{s}}\right)^{0.14}
$$

By substituting the Colburn $j$-factors as $N u / \operatorname{RePr}^{1 / 3}$ into Eq. 17, the Nusselt number equation was derived for the smooth tube in the turbulent flow regime (similar equations can be derived for the laminar and transitional flow regimes) as: 
Table 5. The heat transfer values of the variables in equations 13 and 14 for the Colburn $j$-factor equations, for different heat fluxes at the station $x / D_{i}=246$

\begin{tabular}{|c|c|c|c|c|c|c|c|c|c|c|c|c|}
\hline \multirow[b]{3}{*}{$\dot{q}\left[k W m^{-2}\right.$} & \multicolumn{3}{|c|}{ Smooth tube } & \multicolumn{9}{|c|}{ Twist ratios } \\
\hline & & & & \multicolumn{3}{|c|}{$y=3$} & \multicolumn{3}{|c|}{$y=4$} & \multicolumn{3}{|c|}{$y=5$} \\
\hline & 2 & 3 & 4 & 2 & 3 & 4 & 2 & 3 & 4 & 2 & 3 & 4 \\
\hline$R e_{c r, b}$ & 3053 & 3164 & 3266 & 593 & 819 & 1093 & 669 & 951 & 1172 & 1023 & 1108 & 1278 \\
\hline $\boldsymbol{R} e_{c r, e}$ & 3331 & 3452 & 3565 & 1125 & 1274 & 1404 & 1027 & 1418 & 1524 & 1604 & 1683 & 1775 \\
\hline TFR & 278 & 288 & 299 & 532 & 455 & 311 & 358 & 467 & 352 & 581 & 575 & 497 \\
\hline & \multicolumn{12}{|c|}{ Laminar values } \\
\hline$a_{L}$ & -- & -- & -- & -- & -- & -- & $7.06 \times 10^{9}$ & 32272 & $2.17 \times 10^{8}$ & 820 & 35489 & 319933 \\
\hline$c_{L}$ & -1.23 & -1.32 & -1.43 & -- & -- & -- & -4.1 & -2.12 & -3.32 & -1.63 & -2.15 & -2.41 \\
\hline$d_{L}$ & 24.5 & 111 & 314 & -- & -- & -- & $1.07 \times 10^{10}$ & 48915 & $3.28 \times 10^{8}$ & 1329 & 57516 & 518502 \\
\hline & \multicolumn{12}{|c|}{ Transitional values } \\
\hline$a_{R}$ & -- & -- & -- & 1.04 & 5.04 & 52.7 & 0.113 & 0.21 & 0.0843 & 0.023 & 0.0672 & 0.162 \\
\hline$c_{R}$ & 6.25 & 5.63 & 5.77 & -0.538 & -0.764 & -1.09 & -0.282 & -0.38 & -0.255 & -0.117 & -0.268 & -0.386 \\
\hline$d_{R}$ & $4.62 \times 10^{-25}$ & $5.44 \times 10^{-23}$ & $1.41 \times 10^{-23}$ & 1.44 & 7.01 & 74.7 & 0.171 & 0.318 & 0.128 & 0.0374 & 0.109 & 0.263 \\
\hline & \multicolumn{12}{|c|}{ Turbulent values } \\
\hline$a_{T}$ & -- & -- & -- & 2.49 & 3.17 & 4.05 & 1.32 & 1.66 & 2.14 & 0.603 & 0.575 & 2.43 \\
\hline$c_{T}$ & -0.152 & -0.207 & -0.228 & -0.67 & -0.708 & -0.739 & -0.642 & -0.673 & -0.701 & -0.564 & -0.559 & -0.562 \\
\hline$d_{T}$ & 0.016 & 0.0248 & 0.0296 & 3.46 & 4.41 & 5.62 & 2.00 & 2.51 & 3.24 & 0.977 & 0.932 & 0.982 \\
\hline & \multicolumn{12}{|c|}{ Deviations from experimental data } \\
\hline Average & -0.466 & -0.052 & -2.11 & -4.73 & -6.32 & -5.83 & -3.05 & -4.49 & -5.37 & -1.22 & -2.87 & -5.25 \\
\hline $\operatorname{Max}$ & 8.82 & 5.75 & 6.87 & 5.62 & 6.63 & 5.63 & 3.92 & 5.03 & 4.25 & 2.69 & 4.84 & 1.58 \\
\hline
\end{tabular}




$$
N u_{T}(x)=0.016[\operatorname{Re}(x)]^{0.848}[\operatorname{Pr}(x)]^{1 / 3}\left(\frac{\mu_{b}}{\mu_{s}}\right)^{0.14}
$$

which compares reasonably well with the equation of Ghajar and Tam [12]:

$$
N u_{T}=0.023 \operatorname{Re}^{0.8} \operatorname{Pr}^{0.385}\left(\frac{x}{D}\right)^{-0.0054}\left(\frac{\mu_{b}}{\mu_{s}}\right)^{0.14}
$$

The results for the tubes with a twisted tape insert with a twist ratio of 5 and a heat flux of $2 \mathrm{~kW} / \mathrm{m}^{2}$ (results shown in Fig. 10 and variables from Table 5) are as follows for laminar flow:

$$
j_{L}(x)=820 y^{0.3}[\operatorname{Re}(x)]^{-1.63}\left(\frac{\mu_{b}}{\mu_{s}}\right)^{0.14}
$$

and for transitional flow:

$$
j_{R}(x)=0.023 y^{0.3}[\operatorname{Re}(x)]^{-0.117}\left(\frac{\mu_{b}}{\mu_{s}}\right)^{0.14}
$$

and for turbulent flow:

$$
j_{T}(x)=0.603 y^{0.3}[\operatorname{Re}(x)]^{-0.564}\left(\frac{\mu_{b}}{\mu_{s}}\right)^{0.14}
$$

Although only the Colburn $j$-factor equations for a heat flux of $2 \mathrm{~kW} / \mathrm{m}^{2}$ and a twist ratio of 5 were given above, the equations for the heat fluxes of 3 and $4 \mathrm{~kW} / \mathrm{m}^{2}$ and twist ratios of 3 and 4 can be determined directly from Table 5 .

The equations developed for the Colburn $j$-factors were compared to the experimental data and it was found that the equations estimated the experimental data on average to within $\pm 6 \%$, with a maximum error of $+9 \%$.

\subsection{Twist ratio}

The Colburn $j$-factor results for the same heat flux of $2 \mathrm{~kW} / \mathrm{m}^{2}$, but with twist ratios of 3,4 and 5, are presented in Fig. 11 at $x / D_{i}=246$. The results are also compared to the smooth tube 
at the same $x / D_{i}$, value. The results show that the Colburn $j$-factors increased as the twist ratios decreased from $y=5$ to $y=3$. This can be expected as the twist ratio of $y=3$ will induce more radial rotation to the flow (when compared to the other twist ratios) and will increase the longitudinal flow path through the tube. For this reason, there were less experimental data points in the laminar flow region, and transition occurred earlier.

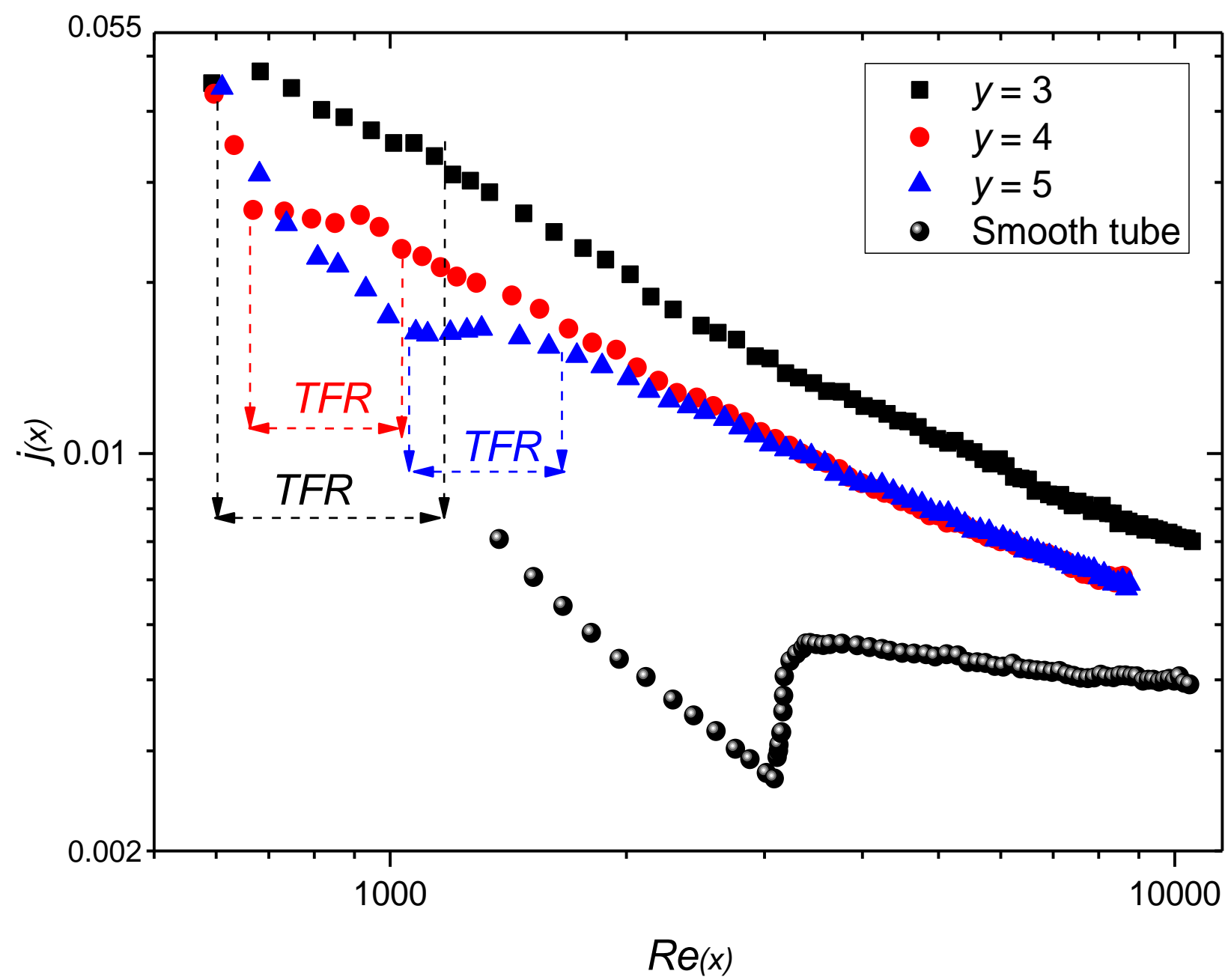

Fig. 11. Local Colburn $j$-factors as a function of local Reynolds numbers at $x / D=246$ and a heat flux of $2 \mathrm{~kW} / \mathrm{m}^{2}$, for twist ratios of 3,4 and 5 for the smooth tube. $T F R$ is the transitional flow regime, so that $T F R=$ $R e_{c r, e}-R e_{c r, b}$ 
In general, transition started earlier as the twist ratio decreased. Transition in Fig. 11 for a twist ratio of $y=3$ started at a Reynolds number of 593. For a twist ratio of $y=4$, it was at a Reynolds number of 669 , and for a twist ratio of $y=5$, it was at a Reynolds number of 1023 . For the smooth tube case, transition started at a Reynolds number of 3053 at a heat flux of $2 \mathrm{~kW} / \mathrm{m}^{2}$. For a heat flux of $3 \mathrm{~kW} / \mathrm{m}^{2}$, it was at a Reynolds number of 3164 , and for a heat flux of $4 \mathrm{~kW} / \mathrm{m}^{2}$, it was at a Reynolds number of 3266 . It ended for the smooth tube at the Reynolds numbers 3331,3452 and 3565 for heat fluxes of 2,3 and $4 \mathrm{~kW} / \mathrm{m}^{2}$ respectively.

The early transition is attributed to the increased flow disturbances as the twist ratio reduced. As shown in Fig. 11, for the same heat flux, the twisted tape insert with the lowest twist $(y=3)$, ratio caused most disturbances, and produced the earliest transition $(R e=593)$. This caused a thinner thermal boundary layer and thus the highest heat transfer coefficients. If twisted tapes only are compared the twisted tape with the highest twist ratio $(y=5)$, delayed transition $(R e=1023)$ the most as it caused the smallest disturbances in the thermal boundary. The tube that will cause no disturbances in the development of the thermal boundary layer is the smooth tube. For this reason, it delayed transition $(R e=3053)$ the most and it had the lowest heat transfer coefficients.

In general, it was also found that the difference between the Reynolds numbers at the end of transition and at the beginning of transition (TFR) increased as the twist ratio increased. At a heat flux of $3 \mathrm{~kW} / \mathrm{m}^{2}$, the $T F R$ values were 455,467 and 575 respectively. This trend was found in all the data except for one point at a heat flux of $4 \mathrm{~kW} / \mathrm{m}^{2}$ and a twist ratio of 3 . At this point, the transition point was probably not that accurate, as experimental data points in the laminar flow regime were challenging to collect. At these low Reynolds numbers, the associated low mass 
flow rates caused the water outlet temperatures to rise beyond the maximum material specifications of the experimental set-up.

\subsection{Heat flux}

The effects of different heat fluxes on a tube with a twisted tape insert with a twist ratio of 4 , as a function of the Reynolds number, are illustrated in Fig. 12. Similar to the results obtained by Tam and Ghajar [46] and Everts [18], it follows from Fig. 12 that higher heat fluxes delayed the transition from laminar to transitional flow. Although these works were conducted at a constant heat flux the delayed transitions were also found by Meyer and Olivier [1, 20, 22]. In the laminar flow regime, the heat transfer coefficients increased with heat flux as the thermal gradient between the fluid and wall increased. This increased the strengths of the buoyancy forces which decreased the thermal boundary layer thickness. The heat transfer coefficients increased as the thermal boundary layer decreased. Higher heat fluxes, increased both the upper and lower limits of the transitional flow regime. The effect of heating is that transition is delayed or to stabilize the flow [46] and thus transition occurred at a higher critical Reynolds number.

Furthermore, the TFR widths decreased as the heat fluxes increased. In the turbulent flow regime, the results were independent of heat flux. This can be expected as similar results were found for all the heat fluxes in smooth tubes and tubes with twisted tape inserts. At Reynolds numbers higher than approximately 5 000, the Colburn $j$-factor results for different heat fluxes diverged from each other. The reason for this is that the temperature difference uncertainties between the tube wall and the mean fluid temperatures increased with increasing mass flow rates (and associated Reynolds numbers). 


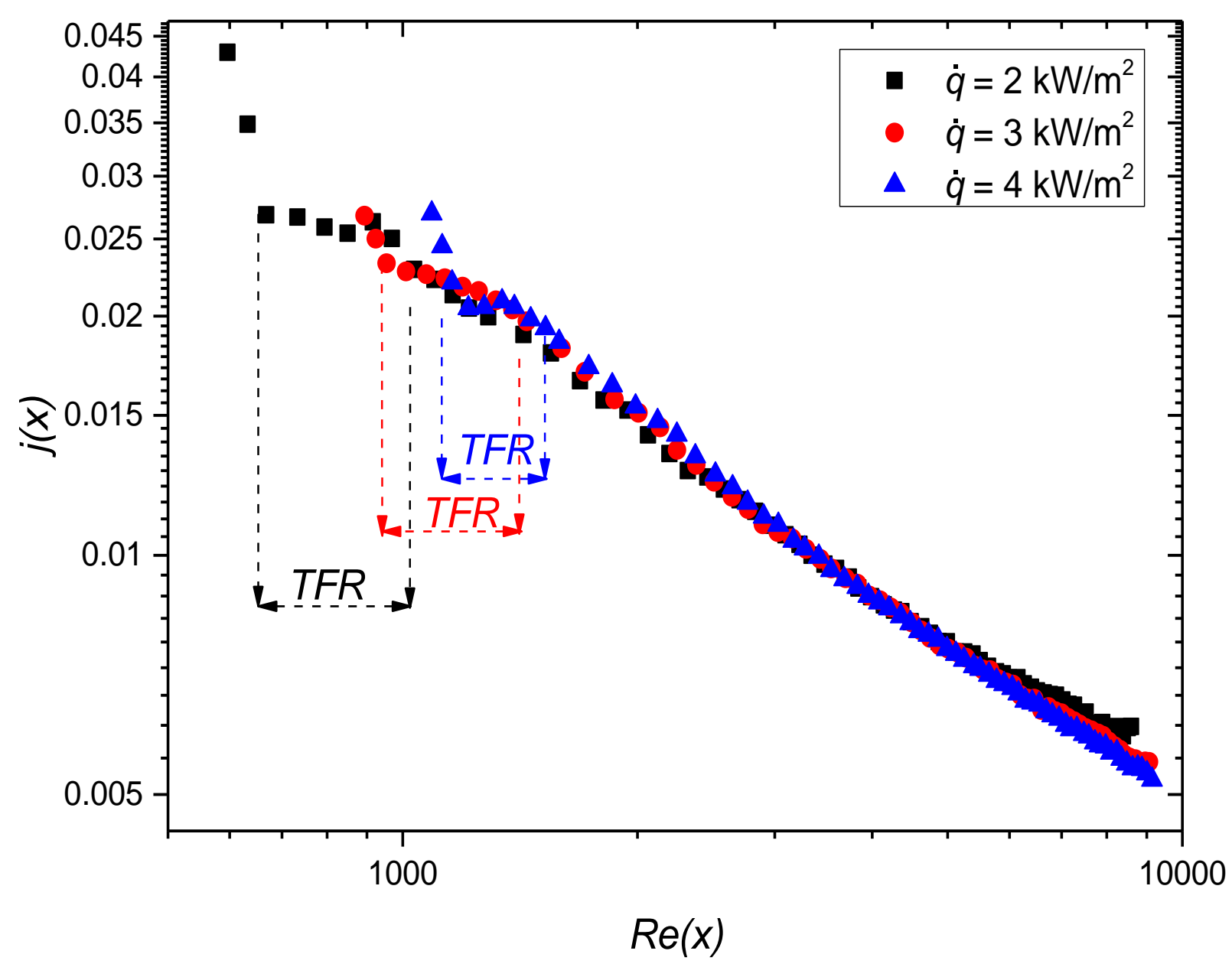

Fig. 12. Local Colburn $j$-factors as a function of local Reynolds numbers at $x / D_{i}=246$ in a tube with a twist ratio of $y=4$, and varying heat fluxes of 2,3 and $4 \mathrm{~kW} / \mathrm{m}^{2}$. TFR is the transitional flow regime, so that $T F R=R e_{c r, e}-R e_{c r, b}$.

\subsection{Friction factors}

It was more challenging to clearly identify the three different flow regimes with the friction factor data than with the heat transfer data. Using the transition results, $\left(R e_{c r, b}\right)$ and $\left(R e_{c r, e}\right)$, of the Colburn $j$-factor data, friction factor correlations similar to the Colburn $j$-factor equations were developed. For the smooth tube, the diabatic friction factor equation used was: 


$$
f=d\left[R e_{b}\right]^{c}\left(\frac{\mu_{b}}{\mu_{s}}\right)^{0.14}
$$

For the tube with the twisted tape insert, the following equation was used:

$$
f=a y^{b}\left[R e_{b}\right]^{c}\left(\frac{\mu_{b}}{\mu_{s}}\right)^{0.14}
$$

Thus, for the case of a heat flux of $2 \mathrm{~kW} / \mathrm{m}^{2}$ and in the laminar flow regime for a smooth tube, the friction factor can be described as:

$$
f_{L}=48.2\left[R e_{b}\right]^{-0.942}\left(\frac{\mu_{b}}{\mu_{s}}\right)^{0.14}
$$

In the transitional flow regime, the equation is:

$$
f_{R}=2.56 \times 10^{-21}\left[R e_{b}\right]^{5.45}\left(\frac{\mu_{b}}{\mu_{s}}\right)^{0.14}
$$

In the turbulent flow regime, the equation is:

$$
f_{T}(x)=0.209\left[R e_{b}\right]^{-0.206}\left(\frac{\mu_{b}}{\mu_{s}}\right)^{0.14}
$$

For a tube with a twisted tape insert, a heat flux of $2 \mathrm{~kW} / \mathrm{m}^{2}$ and a twist ratio of $y=5$ in the laminar flow regime, it is:

$$
f_{L}=4.28 y^{0.3}\left[R e_{b}\right]^{-0.451}\left(\frac{\mu_{b}}{\mu_{s}}\right)^{0.14}
$$

In the transitional flow regime, the equation is:

$$
f_{R}=10.6 y^{0.3}\left[R e_{b}\right]^{-0.583}\left(\frac{\mu_{b}}{\mu_{s}}\right)^{0.14}
$$

In the turbulent flow regime, it is:

$$
f_{T}(x)=8.94 y^{0.3}\left[R e_{b}\right]^{-0.561}\left(\frac{\mu_{b}}{\mu_{s}}\right)^{0.14}
$$

The ranges of Reynolds numbers in the transitional flow regime with diabatic friction factors are given in Table 6, and the appropriate constants for Eqs. (23) and (24) are summarised in 
Table 6. Ranges of transitional flow regime Reynolds numbers of the diabatic friction factors with the smooth tube and twisted tape inserts at different heat flux boundary conditions

\begin{tabular}{|c|c|c|c|c|c|c|c|c|c|c|c|c|}
\hline \multirow{3}{*}{$\begin{array}{l}\text { Heat } \\
\text { fluxes }(\dot{\boldsymbol{q}}) \\
{\left[\mathrm{kW} / \mathrm{m}^{2}\right]}\end{array}$} & \multicolumn{3}{|c|}{ Smooth } & \multicolumn{9}{|c|}{ Twist ratios } \\
\hline & \multirow[b]{2}{*}{$\boldsymbol{R} \boldsymbol{e}_{c r, b}$} & \multirow[b]{2}{*}{$\boldsymbol{R} \boldsymbol{e}_{c r, e}$} & \multirow[b]{2}{*}{$T F R$} & \multicolumn{3}{|c|}{$y=3$} & \multicolumn{3}{|c|}{$y=4$} & \multicolumn{3}{|c|}{$y=5$} \\
\hline & & & & $\boldsymbol{R} \boldsymbol{e}_{c r, b}$ & $\boldsymbol{R} \boldsymbol{e}_{c r, e}$ & $T F R$ & $\boldsymbol{R} \boldsymbol{e}_{c r, b}$ & $R e_{c r, e}$ & $T F R$ & $\boldsymbol{R} \boldsymbol{e}_{c r, b}$ & $\boldsymbol{R} \boldsymbol{e}_{c r, e}$ & $T F R$ \\
\hline 2 & 3041 & 3292 & 251 & 540 & 1091 & 551 & 609 & 977 & 368 & 923 & 1504 & 581 \\
\hline 3 & 3152 & 3411 & 259 & 739 & 1167 & 428 & 814 & 1308 & 494 & 1067 & 1630 & 563 \\
\hline 4 & 3177 & 3507 & 330 & 983 & 1361 & 378 & 1049 & 1485 & 436 & 1182 & 1670 & 488 \\
\hline
\end{tabular}


Table 7. The diabatic friction factor values of the variables in equations 23 and 24 for the different heat fluxes, between the two pressure taps

\begin{tabular}{|c|c|c|c|c|c|c|c|c|c|c|c|c|}
\hline \multirow[b]{3}{*}{$\dot{q}\left[k W m^{-2}\right]$} & \multicolumn{3}{|c|}{ Smooth tube } & \multicolumn{9}{|c|}{ Twist ratios } \\
\hline & & & & \multicolumn{3}{|c|}{$y=3$} & \multicolumn{3}{|c|}{$y=4$} & \multicolumn{3}{|c|}{$y=5$} \\
\hline & 2 & 3 & 4 & 2 & 3 & 4 & 2 & 3 & 4 & 2 & 3 & 4 \\
\hline$R e_{c r, b}$ & 3041 & 3152 & 3177 & 540 & 739 & 983 & 609 & 814 & 1049 & 923 & 1067 & 1182 \\
\hline $\boldsymbol{R} e_{c r, e}$ & 3292 & 3411 & 3507 & 1091 & 1167 & 1361 & 977 & 1308 & 1485 & 1504 & 1630 & 1670 \\
\hline TFR & 251 & 259 & 330 & 551 & 428 & 378 & 368 & 494 & 436 & 581 & 563 & 488 \\
\hline & \multicolumn{12}{|c|}{ Laminar values } \\
\hline$a_{L}$ & -- & -- & -- & -- & -- & -- & 1.37 & 8.83 & 1.54 & 4.28 & 3.46 & 14.9 \\
\hline$c_{L}$ & -0.942 & -0.910 & -1.02 & -- & -- & -- & -0.26 & -0.554 & -0.295 & -0.451 & -0.43 & -0.641 \\
\hline$d_{L}$ & 48.2 & 39.3 & 93.5 & -- & -- & -- & 2.08 & 13.4 & 2.33 & 6.94 & 5.61 & 24.1 \\
\hline \multicolumn{13}{|c|}{ Transitional values } \\
\hline$a_{R}$ & -- & -- & -- & 34.6 & 20.9 & 39.4 & 7.48 & 1.81 & 2.56 & 10.6 & 6.30 & 3.44 \\
\hline$c_{R}$ & 5.45 & 5.69 & 3.48 & -0.683 & -0.609 & -0.694 & -0.519 & -0.320 & -0.367 & -0.583 & -0.513 & -0.433 \\
\hline$d_{R}$ & $2.56 \times 10^{-21}$ & $3.14 \times 10^{-22}$ & $1.72 \times 10^{-14}$ & 48.1 & 29.1 & 54.7 & 11.3 & 2.74 & 3.88 & 17.2 & 10.2 & 5.57 \\
\hline & \multicolumn{12}{|c|}{ Turbulent values } \\
\hline$a_{T}$ & -- & -- & -- & 15.9 & 16.2 & 16.5 & 10.3 & 9.92 & 10.5 & 8.94 & 8.61 & 8.25 \\
\hline$c_{T}$ & -0.206 & -0.211 & -0.195 & -0.577 & -0.579 & -0.580 & -0.560 & -0.557 & -0.561 & -0.561 & -0.556 & -0.552 \\
\hline$d_{T}$ & 0.209 & 0.216 & 0.187 & 22.1 & 22.5 & 22.9 & 15.6 & 15.04 & 15.8 & 14.5 & 13.9 & 13.4 \\
\hline & \multicolumn{12}{|c|}{ Deviations from experimental data } \\
\hline Average & -1.02 & -0.805 & -0.487 & -0.685 & -0.821 & -1.50 & -0.446 & -0.0918 & -0.661 & -0.767 & -1.55 & -0.756 \\
\hline $\operatorname{Max}$ & 8.62 & 1.40 & 5.61 & 2.88 & 2.78 & 2.98 & 0.954 & 1.66 & 1.03 & 0.814 & 0.0836 & 0.874 \\
\hline
\end{tabular}


Table 7 for different twist ratios and heat fluxes. In Table 7, the predicted results from the equations are compared to the measurements of this study and a maximum error of $8 \%$ was obtained. Comparing the start of transition results $\left(R e_{c r, b}\right)$, end of transition results $\left(R e_{c r, e}\right)$ and Coburn $j$-factor values in Table 4 with the friction factor data in Table 6 reveals small differences of a maximum of $14 \%$. The reason is that, for the Colburn $j$-factor data, the local Reynolds number was based on the local temperatures at station 19 at $x / D_{i}=246$, while the friction factor was based on the bulk temperature positioned in the centre of the two pressure taps, between stations 16 and 17 at $x / D_{i}=198$.

The results of the diabatic friction factors for the tube with twisted tape inserts with twist ratios of 3, 4 and 5 are shown in Fig. 13 for a heat flux of $2 \mathrm{~kW} / \mathrm{m}^{2}$. The results show that the transitional flow regimes were not as well defined as the heat transfer data. However, it correctly shows that the friction factor increased as the twist ratio decreased. The reason is that, as the twist ratio decreased, the average lateral flow path length increased. The twisted tape surface area for friction also increased. Furthermore, the $T F R$ widths decreased as the twist ratios increased.

The effect of heat flux on friction factor for a tube with a twisted tape insert and a twist ratio of 5 is given in Fig. 14. It shows that, in the laminar and transitional flow regimes, an increase in heat flux decreased the friction factor. The higher heat fluxes increased the wall surface temperature, which decreased the water viscosity and thus shear stress on the wall. Most probably, the secondary flow effects (that would increase the friction factors) were negligible as, in general, no temperature differences were found between the top of the wall and the bottom of the wall at the same measuring station. In the turbulent flow regime, the heat flux had no effect 
on the friction factor. This can be expected as the heat transfer data (Fig. 12) performed similarly, and the same trend was found when using the linear line method.

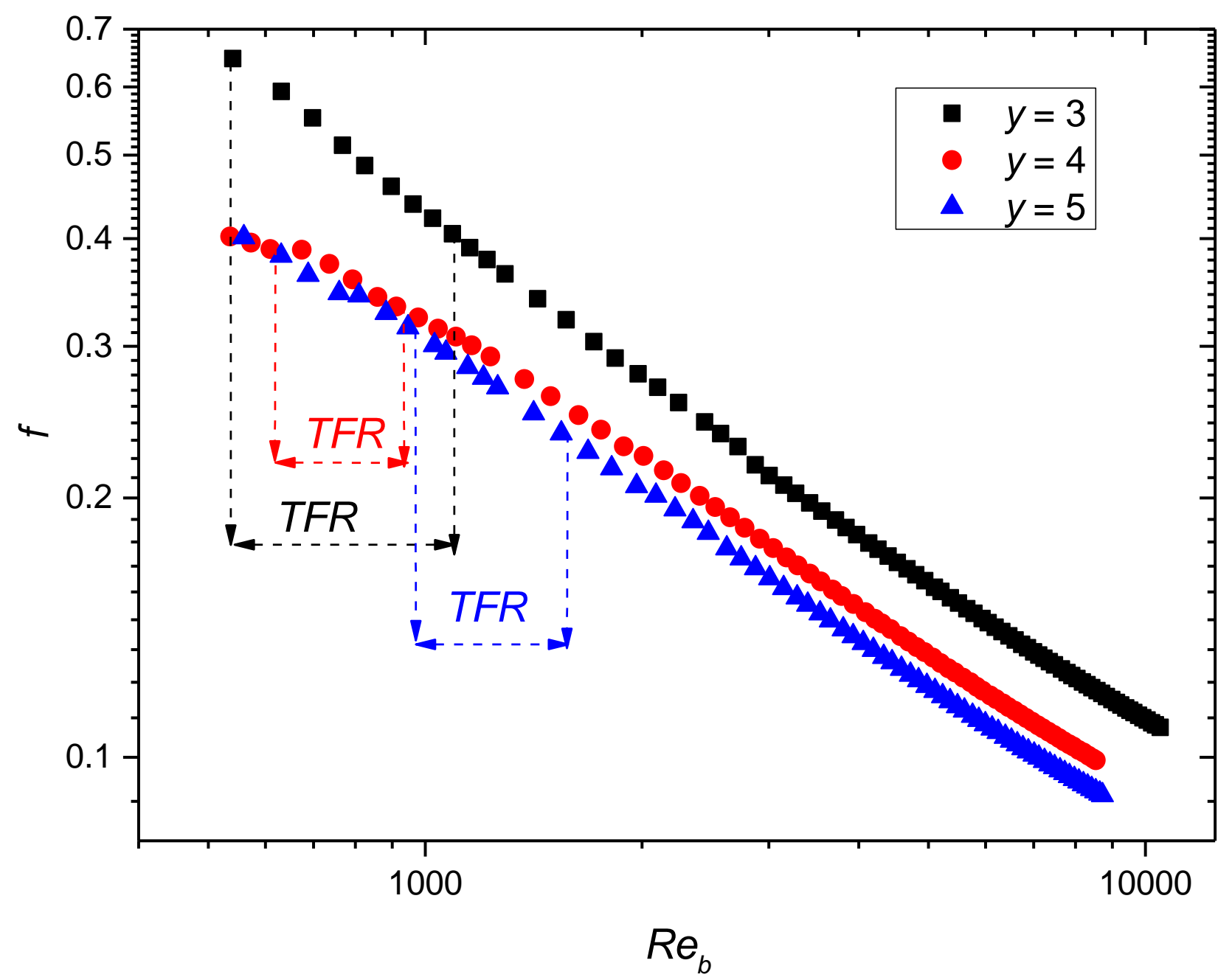

Fig. 13. Friction factors as a function of Reynolds numbers at a heat flux of $2 \mathrm{~kW} / \mathrm{m}^{2}$, for twist ratios of 3,4 and 5 . 


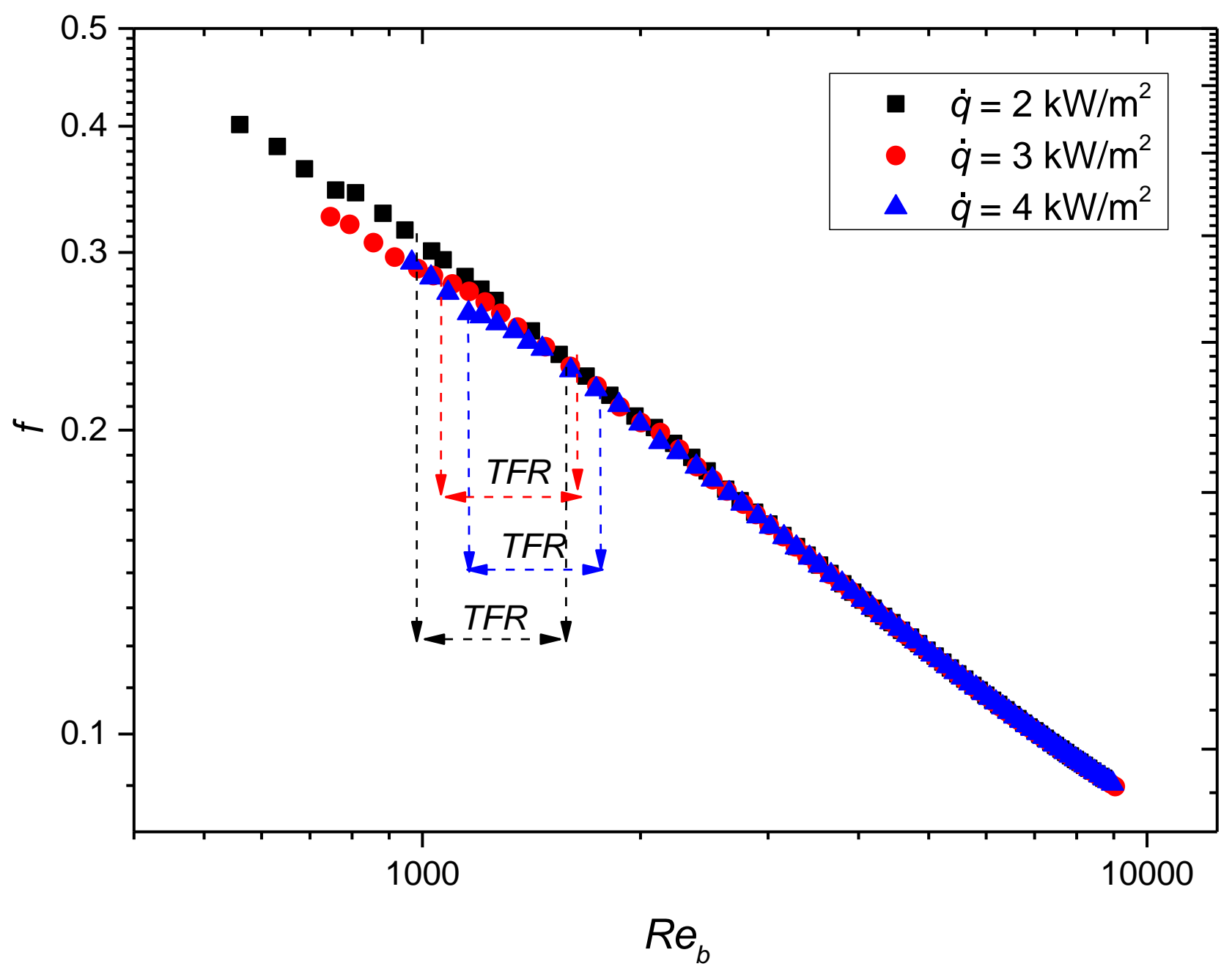

Fig. 14. Friction factors as a function of Reynolds numbers in a tube with a twist ratio of $y=5$, and varying heat fluxes of 2,3 and $4 \mathrm{~kW} / \mathrm{m}^{2}$.

The physical mechanisms that caused the changes in the friction factors as function of Reynolds number, critical Reynolds number, twist ratio and heat fluxes are the same as for the heat transfer data. For the same heat flux, the flow disturbances caused by the twisted tapes increased (as the twist ratios decreased) the flow velocity gradients and thus shear stresses on the wall. This increases the pressure drops and thus friction factors. 
A higher heat flux increased the temperature differences in the fluid. The fluid near the wall had a higher temperature and lower density than those close tube center line. This temperature difference produced mixed convection (Nusselt numbers higher than 4.36 in the smooth tube showed that the flow regime was not forced convection but mixed convection). The changes in flow regime caused the velocity profile of the fluid to change. In these cases, it changed the shear stress and fluid density of the flow. The shear stress increased when the heat fluxes increased, but the fluid density decreased. However, the increases in the shear stresses were more than the decreases in density and therefore the friction factors increased [46].

\section{Conclusions}

An experimental investigation of the transitional flow regime with three twisted tape inserts with twist ratios of 3,4 and 5 were conducted. The range of Reynolds numbers in the experiments in general spanned all three the flow regimes of laminar, transitional and turbulent. A calming section and squared-edged inlet was used. Experiments were conducted at three different heat fluxes $\left(2,3\right.$ and $\left.4 \mathrm{~kW} / \mathrm{m}^{2}\right)$ and the heat transfer coefficients and friction factors were determined. The results were also compared to a smooth tube without any twisted tape inserts. A total of 865 experiments were conducted.

Two independent, yet complementary methods, were used to determine the boundaries where transition started and ended. The first method was the standard deviation method in which the temperature deviations at each measuring station were determined. The second method was to construct three linear curve fits on a $\log -\log$ scale of Colburn $j$-factors as a function of the Reynolds numbers. The curve fits made it possible for correlations to be developed for the nondimensionalised heat transfer coefficients (Colburn $j$-factors) and friction factors, which took into consideration the twist ratio, heat flux and Reynolds number. 
For the same heat flux, it was found that the Colburn $j$-factors increased as the twist ratios decreased, and transition started earlier. When the twist ratio was kept constant, and the heat fluxes were varied, higher heat fluxes delayed the transition from laminar to transitional flow. Furthermore, the TFR widths decreased as the heat fluxes increased.

For friction factors, it was found that friction factors increased as the twist ratio decreased.

The TFR widths also decreased as the twist ratios increased. When both the twist ratio and the Reynolds number were kept constant, an increase in heat flux was found to decrease the friction factor.

\section{Acknowledgement}

The authors appreciate the sponsorship received from the following institutions and organisations throughout the period of the experimentation: the National Research Foundation (NRF), the University of Pretoria's Institutional Research Theme (IRT) on Energy, the Solar Hub between Stellenbosch University and the University of Pretoria, supported by the Department of Science and Technology, the Tertiary Education Support Programme (TESP) of Eskom, the National Advisory Council on Innovation (NACI), the National Hub for the Postgraduate Programme in Energy-efficiency and Demand-side Management (EEDSM Hub) of the University of Pretoria and the Council for Scientific and Industrial Research (CSIR).

\section{References}

[1] J. P. Meyer and J. A. Olivier, "Heat transfer and pressure drop characteristics of smooth horizontal tubes in the transitional flow regime," Heat Transfer Engineering, vol. 35, pp. 1246-1253, 2014.

[2] S. Rozzi, R. Massini, G. Paciello, G. Pagliarini, S. Rainieri, and A. Trifir, "Heat treatment of fluid foods in a shell and tube heat exchanger: Comparison between smooth and helically corrugated wall tubes," Journal of Food Engineering, vol. 79, pp. 249-254, 2007.

[3] S. Liu and M. Sakr, "A comprehensive review on passive heat transfer enhancements in pipe exchangers," Renewable and Sustainable Energy Reviews, vol. 19, pp. 64-81, 2013. 
[4] Z. Zhang, D. Ma, X. Fang, and X. Gao, "Experimental and numerical heat transfer in a helically baffled heat exchanger combined with one three-dimensional finned tube," Chemical Engineering and Processing: Process Intensification, vol. 47, pp. 1738-1743, 2008.

[5] J. P. Meyer, "Heat transfer in tubes in the transitional flow regime," in Proceedings of the 15th International Heat Transfer Conference Kyoto, Japan, 2014, pp. 1-21.

[6] N. T. Obot, E. B. Esen, and T. J. Rabas, "The role of transition in determining friction and heat transfer in smooth and rough passages," International Journal of Heat and Mass Transfer, vol. 33, pp. 2133-2143, 1990.

[7] Ashrae, Fluid flow, ASHRAE Handbook - Fundamentals, American Society of Heating, Refrigerating and Air-Conditioning Engineers, Inc., Atlanta vol. 30329, 2009.

[8] Y. A. Cengel and A. J. Ghajar, Heat and mass transfer: fundamentals \& applications, 5th ed. in SI units. ed. New York: Mcgraw Hill Education, 2015.

[9] Z. Duan, "Fully developed turbulent flow pressure drop in circular and noncircular ducts," Journal of Fluids Engineering, vol. 134, pp. 1-10, 2012.

[10] Y. S. Muzychka, Z. P. Duan, and M. M. Yovanovich, "Fluid friction and heat transfer in microchannels, microfluidics and nanofluidics handbook: Chemistry physics and life science principles," Taylor and Francis, pp. 477-610, 2011.

[11] Z. Duan, "New correlative models for fully developed turbulent heat and mass transfer in circular and noncircular ducts," Transaction of ASME, Journal of Heat Transfer, vol. 134, pp. 1-6, 2012.

[12] A. J. Ghajar and L. M. Tam, "Heat transfer measurements and correlations in the transition region for a circular tube with three different inlet configurations," Experimental Thermal and Fluid Science, vol. 8, pp. 79-90, 1994.

[13] A. J. Ghajar and L. M. Tam, "Laminar-transition-turbulent forced and mixed convective heat transfer correlations for pipe flows with different inlet configurations," presented at the Winter Annual Meeting of the Amenrican Society of Mechanical Engineers, 1991.

[14] A. J. Ghajar and Y. H. Zurigat, "Microcomputer-assisted heat transfer measurements/analysis in a circular tube," International Journal of Applied Engineering Education, vol. 7, pp. 125-134, 1991.

[15] L. M. Tam and A. J. Ghajar, "Transitional heat transfer in plain horizontal tubes," Heat Transfer Engineering, vol. 27, pp. 23-38, 2006.

[16] L. M. Tam and A. J. Ghajar, "The unusual behavior of local heat transfer coefficient in a circular tube with a bell-mouth inlet," vol. 16, pp. 187-194, 1998.

[17] J. Dirker, J. P. Meyer, and D. V. Garach, "Inlet flow effects in micro-channels in the laminar and transitional regimes on single-phase heat transfer coefficients and friction factors," International Journal of Heat and Mass Transfer, vol. 77, pp. 612-626, 2014.

[18] M. Everts, "Heat transfer and pressure drop of developing flow in the transitional flow regime," Master of Engineering, Deparment of Mechanical and Aeronautical Engineering, University of Pretoria, Pretoria, 2014.

[19] J. P. Meyer, T. J. McKrell, and K. Grote, "The influence of multi-walled carbon nanotubes on single-phase heat transfer and pressure drop characteristics in the transitional flow regime of smooth tubes," International Journal of Heat and Mass Transfer, vol. 58, pp. 597-609, 2013. 
[20] J. A. Olivier and J. P. Meyer, "Single-phase heat transfer and pressure drop of the cooling of water inside smooth tubes for transitional flow with different inlet geometries (RP1280)," HVAC and Research, vol. 16, pp. 471-496, 2010.

[21] M. Everts and J. P. Meyer, "Heat transfer of developing flow in the transitional flow regime," in Proceedings of the 1st Thermal and Fluid Engineering Summer Conference, TFESC New York City, USA, 2015, pp. 1-13.

[22] J. P. Meyer and J. A. Olivier, "Transitional flow inside enhanced tubes for fully developed and developing flow with different types of inlet disturbances: Part II-heat transfer," International Journal of Heat and Mass Transfer, vol. 54, pp. 1598-1607, 2011.

[23] S. W. Hong and A. E. Bergles, "Augmentation of laminar flow heat transfer in tubes by means of twisted-tape inserts," Journal of Heat Transfer, vol. 98, pp. 251-256, 1976.

[24] K. Wongcharee and S. Eiamsa-ard, "Friction and heat transfer characteristics of laminar swirl flow through the round tubes inserted with alternate clockwise and counterclockwise twisted-tapes," International Communications in Heat and Mass Transfer, vol. 38, pp. 348-352, 2011.

[25] S. K. Saha, A. Dutta, and S. K. Dhal, "Friction and heat transfer characteristics of laminar swirl flow through a circular tube fitted with regularly spaced twisted-tape elements," International Journal of Heat and Mass Transfer, vol. 44, pp. 4211-4223, 2001.

[26] K. Watanabe, T. Taira, and Y. Mori, "Heat transfer augementation in tubular flow by twisted tapes at high temperatures and optimum performance," Heat Transfer - Japanese Research, vol. 12, pp. 1-31, 1983.

[27] P. S. Bandyopadhyay, U. N. Gaitonde, and S. P. Sukhatme, "Influence of free convection on heat transfer during laminar flow in tubes with twisted tapes," Experimental Thermal and Fluid Science, vol. 4, pp. 577-586, 1991.

[28] A. W. Date, "Prediction of fully-developed flow containing a twisted-tape," International journal of heat and mass transfer, vol. 17, pp. 845-859, 1974.

[29] A. W. Date and U. N. Gaitonde, "Development of correlations for predicting characteristics of laminar flow in a tube fitted with regularly spaced twisted-tape elements," Experimental Thermal and Fluid Science, vol. 3, pp. 373-382, 1990.

[30] S. Eiamsa-ard, C. Thianpong, P. Eiamsa-ard, and P. Promvonge, "Thermal characteristics in a heat exchanger tube fitted with dual twisted tape elements in tandem," International Communications in Heat and Mass Transfer, vol. 37, pp. 39-46, 2010.

[31] H. Bas and V. Ozceyhan, "Heat transfer enhancement in a tube with twisted tape inserts placed separately from the tube wall," Experimental Thermal and Fluid Science, vol. 41, pp. 51-58, 2012.

[32] P. Seemawute and S. Eiamsa-ard, "Thermohydraulics of turbulent flow through a round tube by a peripherally-cut twisted tape with an alternate axis," International Communications in Heat and Mass Transfer, vol. 37, pp. 652-659, 2010.

[33] S. Eiamsa-ard, K. Wongcharee, P. Eiamsa-ard, and C. Thianpong, "Heat transfer enhancement in a tube using delta-winglet twisted tape inserts," Applied Thermal Engineering, vol. 30, pp. 310-318, 2010.

[34] P. Promvonge, "Thermal augmentation in circular tube with twisted tape and wire coil turbulators," Energy Conversion and Management, vol. 49, pp. 2949-2955, 2008.

[35] S. W. Chang and M. H. Guo, "Thermal performances of enhanced smooth and spiky twisted tapes for laminar and turbulent tubular flows," International Journal of Heat and Mass Transfer, vol. 55, pp. 7651-7667, 2012. 
[36] S. W. Chang and B. J. Huang, "Thermal performances of tubular flows enhanced by ribbed spiky twist tapes with and without edge notches," International Journal of Heat and Mass Transfer, vol. 73, pp. 645-663, 2014.

[37] S. W. Chang, Y. J. Jan, and J. S. Liou, "Turbulent heat transfer and pressure drop in tube fitted with serrated twisted tape," International Journal of Thermal Sciences, vol. 46, pp. 506-518, 2007.

[38] S. W. Chang, T. L. Yang, and J. S. Liou, "Heat transfer and pressure drop in tube with broken twisted tape insert," Experimental Thermal and Fluid Science, vol. 32, pp. 489501, 2007.

[39] S. W. Chang, K. W. Yu, and M. H. Lu, "Heat transfer in tubes fitted with single, tiwn and tripple twisted tapes," Journal of Experimental Heat Transfer, vol. 18, pp. 279-294, 2005.

[40] R. M. Manglik and A. E. Bergles, "Characterization of twisted-tape-induced helical swirl flows for enhancement of forced convective heat transfer in single-phase and two-phase flows," Journal of Thermal Science and Engineering Applications, vol. 5, pp. 1-12, 2013.

[41] R. M. Manglik and A. E. Bergles, "Heat transfer and pressure drop correlations for twisted-tape inserts in isothermal tubes: Part I-laminar flows," Journal of Heat Transfer, vol. 115, pp. 881-889, 1993.

[42] B. Donevski and J. Kulesza, "Resistance coefficients of laminar and turbulent flow in swirling ducts," Archiwum Termodynamiki i Spalania [in Polish], vol. 9, pp. 497-506, 1978.

[43] R. K. Nair, "Performance of twisted-tape inserts in laminar and turbulent," M.S., Department of Mechanical Engineering, Iowa State University, Ames, IA, 1986.

[44] P. Bharadwaj, A. D. Khondge, and A. W. Date, "Heat transfer and pressure drop in a spirally grooved tube with twisted tape insert," International Journal of Heat and Mass Transfer, vol. 52, pp. 1938-1944, 2009.

[45] H. K. Tam, L. M. Tam, and A. J. Ghajar, "Effect of inlet geometries and heating on the entrance and fully-developed friction factors in the laminar and transition regions of a horizontal tube," Experimental Thermal and Fluid Science, vol. 44, pp. 680-696, 2013.

[46] L. M. Tam and A. J. Ghajar, "Effect of inlet geometry and heating on the fully developed friction factor in the transition region of a horizontal tube," Experimental thermal and fluid science, vol. 15, pp. 52-64, 1997.

[47] M. Everts, S. R. Ayres, F. A. M. Houwer, C. P. Vanderwagen, N. M. Kotze, and J. P. Meyer, "The influence of surface roughness on heat transfer in the transitional flow regime," in Proceedings of the 15th International Heat Transfer Conference, IHTC-15, Kyoto, Japan, 2014, pp. 1-13.

[48] H. K. Tam, L. M. Tam, A. J. Ghajar, C. Sun, and H. Y. Leung, "Experimental investigation of single-phase friction factor and heat transfer inside the horizontal internally micro-fin tubes in transition region," presented at the ASME-JSME-KSME Joint Fluids Engineering Conference, Hamamatsu, Shizuoka, Japan, 2011.

[49] H. K. Tam, L. M. Tam, A. J. Ghajar, C. Sun, and W. K. Lai, "Experimental investigation of single-phase heat transfer in a horizontal internally micro-fin tube with three different inlet configurations," presented at the ASME 2012 Summer Heat Transfer Conference, Rio Grande, Puerto Rico, 2012.

[50] J. P. Meyer and J. A. Olivier, "Transitional flow inside enhanced tbes for fully developed and developing flow with different types of inlet disturbances: Part I - Adiabatic pressure drops," International Journal of Heat \& Mass Transfer, vol. 54, pp. 1587-1597, 2011. 
[51] F. Durst, S. Ray, B. Unsal, and O. A. Bayoumi, "The development lengths of laminar pipe and channel flows," Journal of Fluids Engineering, vol. 127, pp. 1154-1160, 2005.

[52] W. H. Azmi, K. V. Sharma, R. Mamat, and S. Anuar, "Turbulent forced convection heat transfer of nanofluids with twisted tape insert in a plain tube," in Energy Procedia, 2014, pp. 296-307.

[53] A. Hasanpour, M. Farhadi, and K. Sedighi, "A review study on twisted tape inserts on turbulent flow heat exchangers: The overall enhancement ratio criteria," International Communications in Heat and Mass Transfer, vol. 55, pp. 53-62, 2014.

[54] M. T. Naik, S. S. Fahad, L. Syam Sundar, and M. K. Singh, "Comparative study on thermal performance of twisted tape and wire coil inserts in turbulent flow using $\mathrm{CuO} /$ water nanofluid," Experimental Thermal and Fluid Science, vol. 57, pp. 65-76, 2014.

[55] P. K. Pal and S. K. Saha, "Experimental investigation of laminar flow of viscous oil through a circular tube having integral spiral corrugation roughness and fitted with twisted tapes with oblique teeth," Experimental Thermal and Fluid Science, vol. 57, pp. 301-309, 2014.

[56] T. Wang, F. Wang, A. Fan, and W. Liu, "Laminar heat transfer characteristics in circular tubes with twisted tapes of alternate axes," Huagong Xuebao/CIESC Journal, vol. 65, pp. 316-322, 2014.

[57] S. V. Patil and P. V. Vijay Babu, "Laminar heat transfer augmentation through a square duct and circular tube fitted with twisted tapes," Experimental Heat Transfer, vol. 27, pp. 124-143, 2014.

[58] S. Pal and S. K. Saha, "Laminar flow and heat transfer through a circular tube having integral transverse corrugations and fitted with centre-cleared twisted-tape," Experimental Thermal and Fluid Science, vol. 57, pp. 388-395, 2014.

[59] H. Maddah, M. Alizadeh, N. Ghasemi, and S. R. Wan Alwi, "Experimental study of Al2O3/water nanofluid turbulent heat transfer enhancement in the horizontal double pipes fitted with modified twisted tapes," International Journal of Heat and Mass Transfer, vol. 78, pp. 1042-1054, 2014.

[60] S. D. Salman, A. A. H. Kadhum, M. S. Takriff, and A. B. Mohamad, "Heat transfer enhancement of laminar nanofluids flow in a circular tube fitted with parabolic-cut twisted tape inserts," The Scientific World Journal, vol. 2014, 2014.

[61] W. T. Ji, A. M. Jacobi, Y. L. He, and W. Q. Tao, "Summary and evaluation on singlephase heat transfer enhancement techniques of liquid laminar and turbulent pipe flow," International Journal of Heat and Mass Transfer, vol. 88, pp. 735-754, 2015.

[62] S. Pal and S. K. Saha, "Experimental investigation of laminar flow of viscous oil through a circular tube having integral axial corrugation roughness and fitted with twisted tapes with oblique teeth," Heat and Mass Transfer/Waerme- und Stoffuebertragung, vol. 51, pp. 1189-1201, 2015.

[63] K. Sivakumar, K. Rajan, S. Murali, S. Prakash, V. Thanigaivel, and T. Suryakumar, "Experimental investigation of twisted tape insert on laminar flow with uniform heat flux for enhancement of heat transfer," Journal of Chemical and Pharmaceutical Sciences, vol. 2015-April, pp. 201-205, 2015.

[64] S. Eiamsa-Ard, K. Wongcharee, P. Eiamsa-Ard, and V. Chuwattanakul, "Heat transfer enhancement of turbulent flow through dimpled tubes fitted with twisted tapes," in ICOPE 2015 - International Conference on Power Engineering, 2015. 
[65] M. Tiwari and S. K. Saha, "Laminar flow through a circular tube having transverse ribs and twisted tapes," Journal of Thermal Science and Engineering Applications, vol. 7, 2015.

[66] S. Pal and S. K. Saha, "Laminar fluid flow and heat transfer through a circular tube having spiral ribs and twisted tapes," Experimental Thermal and Fluid Science, vol. 60, pp. 173-181, 2015.

[67] S. Eiamsa-Ard, K. Nanan, K. Wongcharee, K. Yongsiri, and C. Thianpong, "Thermohydraulic Performance of Heat Exchanger Tube Equipped with Single-, Double, and Triple-Helical Twisted Tapes," Chemical Engineering Communications, vol. 202, pp. 606-615, 2015.

[68] S. Eiamsa-Ard, S. Kunlabud, K. Wongcharee, M. Pimsarn, and P. Eiamsa-Ard, "Thermal performance evaluation of micro-fin tube with twisted tape inserts," in ICOPE 2015 International Conference on Power Engineering, 2015.

[69] R. J. Yadav, S. Kore, V. N. Raibhole, and P. S. Joshi, "Development of Correlations for Friction Factor and Heat Transfer Coefficient for Square and Hex Duct with Twisted Tape Insert in Laminar Flow," in Procedia Engineering, 2015, pp. 250-257.

[70] S. Gunes and E. Karakaya, "Thermal Characteristics in a Tube with Loose-Fit Perforated Twisted Tapes," Heat Transfer Engineering, vol. 36, pp. 1504-1517, 2015.

[71] Z. Wang, J. Zhu, R. Tian, and S. Wang, "Laminar flow characteristics in a circular tube fitted with an eccentric twisted tape," Beijing Huagong Daxue Xuebao (Ziran Kexueban)/Journal of Beijing University of Chemical Technology (Natural Science Edition), vol. 42, pp. 50-56, 2015.

[72] Y. Aldali, I. Elbaba, and K. Morad, "Heat transfer enhancement for laminar flow in circular tubes with twisted-tape inserts," Journal of Thermophysics and Heat Transfer, vol. 29, pp. 805-811, 2015.

[73] R. Bhadouriya, A. Agrawal, and S. V. Prabhu, "Experimental and numerical study of fluid flow and heat transfer in a twisted square duct," International Journal of Heat and Mass Transfer, vol. 82, pp. 143-158, 2015.

[74] L. S. Sundar, A. C. M. Sousa, and M. K. Singh, "Heat transfer enhancement of low volume concentration of carbon nanotube-Fe $<$ inf $>3</$ inf $>0<$ inf $>4</$ inf $>/$ water hybrid nanofluids in a tube with twisted tape inserts under turbulent flow," Journal of Thermal Science and Engineering Applications, vol. 7, 2015.

[75] S. Lei, Y. Guo, M. Gui, and Q. Bi, "Experimental study on compound heat transfer enhancement of transverse corrugated tube with full length twisted tapes," Jixie Gongcheng Xuebao/Journal of Mechanical Engineering, vol. 52, pp. 142-146, 2016.

[76] M. K. Abdolbaqi, W. H. Azmi, R. Mamat, N. M. Z. N. Mohamed, and G. Najafi, "Experimental investigation of turbulent heat transfer by counter and co-swirling flow in a flat tube fitted with twin twisted tapes," International Communications in Heat and Mass Transfer, vol. 75, pp. 295-302, 7// 2016.

[77] P. V. Durga Prasad and A. V. S. S. K. S. Gupta, "Experimental investigation on enhancement of heat transfer using Al2O3/water nanofluid in a u-tube with twisted tape inserts," International Communications in Heat and Mass Transfer, vol. 75, pp. 154-161, 7// 2016.

[78] Q. S. Mahdi and N. A. M. Mohammed, "Heat transfer augmentation of laminar nanofluid flow in horizontal tube inserted with twisted tapes," International Journal of Mechanical Engineering and Technology, vol. 7, pp. 225-239, 2016. 
[79] M. M. K. Bhuiya, A. K. Azad, M. S. U. Chowdhury, and M. Saha, "Heat transfer augmentation in a circular tube with perforated double counter twisted tape inserts," International Communications in Heat and Mass Transfer, vol. 74, pp. 18-26, 5// 2016.

[80] A. Boonloi and W. Jedsadaratanachai, "Turbulent Forced Convection and Heat Transfer Characteristic in a Circular Tube with Modified-Twisted Tapes," Journal of Thermodynamics, vol. 2016, 2016.

[81] E. Kannan, C. Balasuthagar, S. Ponsankar, and M. Sivashankar, "Experimental investigation on convective heat transfer characteristics in a circular tube fitted with perforated twisted tape and wire coil," Journal of Chemical and Pharmaceutical Sciences, vol. 9, pp. 2767-2769, 2016.

[82] R. M. Manglik and A. E. Bergles, "Heat transfer enhancement and pressure drop in viscous liquid flows in isothermal tubes with twisted-tape inserts," Wärme- und Stoffübertragung, vol. 27, pp. 249-257, 1992.

[83] R. M. Manglik and A. E. Bergles, "Heat transfer and pressure drop correlations for twisted-tape inserts in isothermal tubes: Part II - transition and turbulent flows," Journal of Heat Transfer, vol. 115, pp. 890-896, 1993.

[84] A. J. Ghajar and K. F. Madon, "Pressure drop measurements in the transition region for a circular tube with three different inlet configurations," Experimental Thermal and Fluid Science, vol. 5, pp. 129-135, 1992.

[85] R. E. Rayle, "Influence of Orifice Geometry on Static Pressure Measurements," ASME Paper No. 59-A-234, 1959.

[86] C. O. Popiel and J. Wojtkowiak, "Simple formulas for thermophysical properties of liquid water for heat transfer calculations (from $0^{\circ} \mathrm{C}$ to $150^{\circ} \mathrm{C}$ )," Heat Transfer Engineering, vol. 19, pp. 87-101, 1998.

[87] P. F. Dunn, Measurement and data analysis for engineering and science, $2 \mathrm{nd}$ edn. ed. New York, USA: CRC Press, Taylor and Francis Group, Boca Raton, 2010.

[88] S. M. Morcos and A. E. Bergles, "Experimental investigation of combined forced and free laminar convection in horizontal tubes," Journal of Heat Transfer, vol. 97, pp. 212219, 1975.

[89] H. Schlichting and K. Gersten, Boundary-layer theory, Germany: Springer-Verlag Berlin Heidelberg, 2017.

[90] V. Gnielinski, "On heat transfer in tubes," International Journal of Heat and Mass Transfer, vol. 63, pp. 134-140, 2013.

[91] S. W. Chang and Y. Zhen, "Enhanced heat transfer with swirl duct under rolling and pitching environment," Journal of Ship Research, vol. 46, pp. 149-166, 2002.

[92] F. L. Test, "Laminar flow heat transfer for fluids and liquids with temperature-dependent viscosity," Journal of Heat Transfer, vol. 90, pp. 385-393, 1968.

[93] R. W. Allen and E. R. G. Eckert, "Friction and heat-transfer measurements to turbulent pipe flow of water ( $\operatorname{Pr}=7$ and 8) at uniform wall heat flux," Journal of Heat Transfer, vol. 86, pp. 301-310, 1964. 